PNL-3206

NUREG/CR-1139

R-3

\title{
An Evaluation of the In-Pile Pressure Data From Instrumented Fuel Assemblies IFA-431 and IFA-432
}

E. R. Bradley

M. E. Cunningham

D. D. Lanning

R. E. Williford

October 1979

Prepared for

the U.S. Nuclear Regulatory Commission

Pacific Northwest Laboratory

Operated for the U.S. Department of Energy

by Battelle Memorial Institute 


\title{
NOTICE
}

This report was prepared as an account of work sponsored by the United States Government. Neither the United States nor the United States Nuclear Regulatory Commission, nor any of their employees, nor any of their contractors, subcontractors, or their employees, makes any warranty, express or implied, or assumes any legal liability or responsibility for the accuracy, completeness or usefulness of any information, apparatus, product or process disclosed, or represents that its use would not infringe privately owned rights.

\author{
PACIFIC NORTHWEST LABORATORY \\ operated by \\ BATTELLE \\ for the \\ UNITED STATES DEPARTMENT OF ENERGY \\ Under Contract EY-76-C-06-1330
}

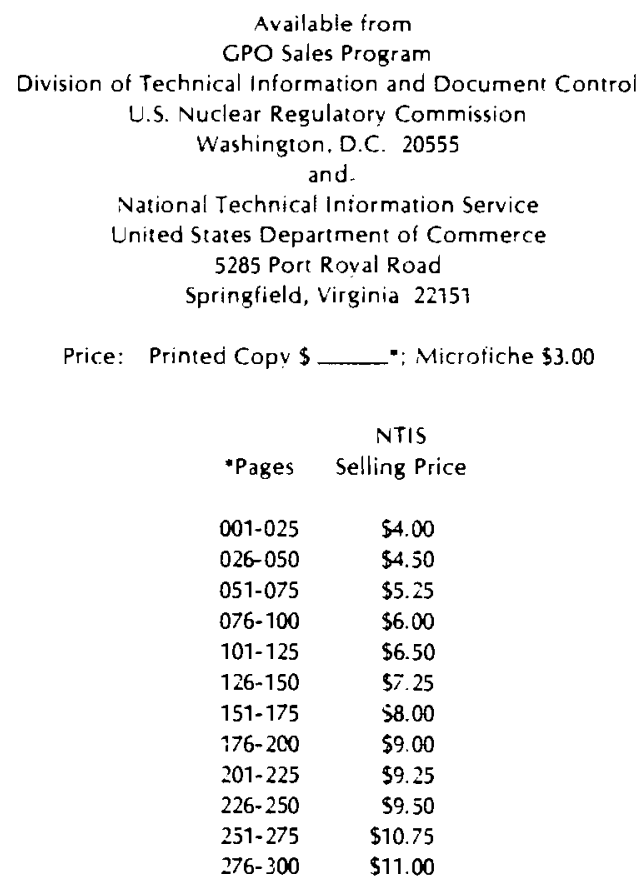


AN EVALUATION OF THE IN-PILE PRESSURE DATA FROM INSTRUMENTED FUEL ASSEMBLIES IFA-431 AND IFA-432
E. R. Bradley
M. E. Cunningham
D. D. Lanning
R. E. Williford

October 1979

Prepared for

the U.S. Nuclear Regulatory Commission under a Related Services Agreement with the U.S. Department of Energy Contract EY-76-C-06-1830

Fin No. B-2043

Prepared by

Nuclear Fuels Section

Materials Department

Pac if ic Northwest Laboratory

Richland, Washington 99352

DDE.Richland, WA 


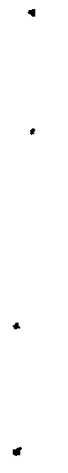




\section{ACKNOWLEDGMENTS}

The authors gratefully acknowledge the support of Dr. W. J. Johnson and H. H. Scott of the Fuel Behavior Research Branch; the assistance of J. A. Christensen, R. W. Miller, and the Halden Project staff during the design and irradiation; and the comments and guidance of C. R. Hann during the course of this work. 


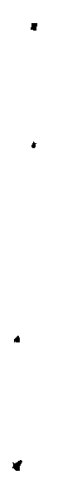




\section{ABSTRACT}

This report includes results of the examination of the in-pile pressure data from instrumented test assemblies IFA-431 and 432. The pressure data have been used to estimate the fission gas release fraction as a function of fuel burnup. Included are comparisons of the estimated release functions and those predicted by three fission gas release models using the experimental temperature histories of the fuel rods. These comparisons show that fuel temperature is the primary factor in determining fission gas release and that burnupenhanced fission gas release is not important in $\mathrm{UO}_{2}$ fuels irradiated to $1700 \mathrm{GJ} / \mathrm{kgU}(20,000 \mathrm{MWd} / \mathrm{MTM})$. 
<smiles>[Mg][Mg]</smiles> 
This report includes the internal pressure data from fuel rods in two of the Nuclear Regulatory Commission/Pacific Northwest Laboratory's instrumented fuel assemblies. Three rods in each assembly were equipped with pressure transducers for monitoring fission gas release during irradiation. The experimental parameters were consistent with current light water reactor fuel and include fuel temperature, fuel density, fuel stability with respect to densification, and burnup. Instrumented fuel assembly 431 (IFA-431) was discharged after achieving burnups in excess of $350 \mathrm{GJ} / \mathrm{kgU}$ ( $4 \mathrm{GWd} / \mathrm{MTM}$ ). Assembly 432 is stil1 being irradiated, but current exposures in the IFA-432 rods are in excess of $1700 \mathrm{GJ} / \mathrm{kgU}$ (20 GWd/MTM).

Meaningful pressure data was obtained from five of the six pressure transducers. Data from all five shows a pressure decrease during the initial stages of irradiation, which is due to the combined effects of fuel densification and helium loss from the fuel rod system. The relative contribution from each of these could not be established and, thus, a range of gas release fractions was calculated from the pressure data. In all cases, the estimated gas release was less than $15 \%$.

The estimated release fractions were compared to the predictions from gas release models currently being used in the GAPCON and FRAPCON series of steadystate fuel performance computer codes. Specifically, the GASREL (Beyer, et al. 1975), FGASRL (Reymann, ed., 1978), and ANS54 (Rausch and Panisko, 1979), subroutines for fission gas release were used in conjunction with the measured temperature/power histories of each rod. From these comparisons, the following has been concluded regarding fission gas release from $\mathrm{UO}_{2}$ fuels.

- Fuel temperature is the predominant factor in fission gas release.

- Fuel density has only a minor influence on fission gas release.

- Burnup-enhanced fission gas release is not significant for exposures up to $1700 \mathrm{GJ} / \mathrm{kgU}$ (20 GWd/MTM). 


\section{CONTENTS}

\section{ACKNOWLEDGMENTS}

ABSTRACT .

SUMMARY AND CONCLUSIONS

INTRODUCTION

IRRADIATION TEST PARAMETERS AND INSTRUMENTATION

REACTOR OPERATION

ASSEMBLY DESCRIPTION

PRESSURE INSTRUMENTATION

EXPERIMENTAL RESULTS

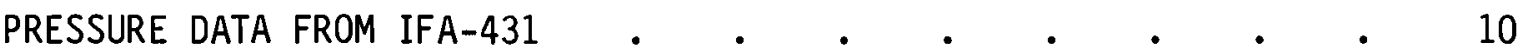

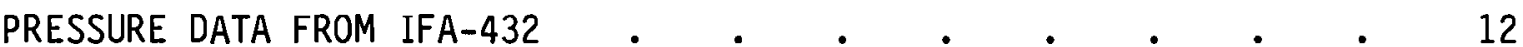

DISCUSSION

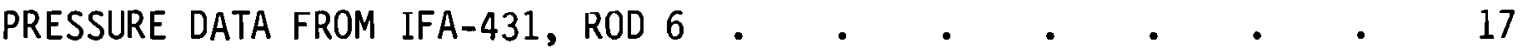

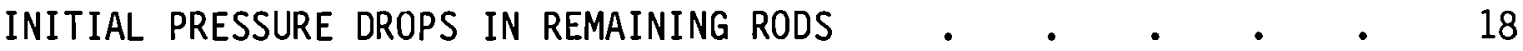

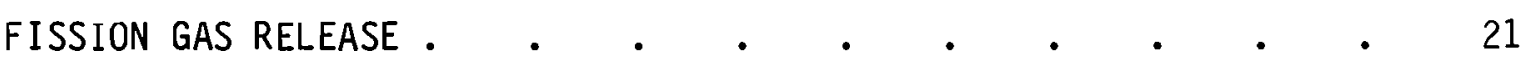

REFERENCES

APPENDIX A: PRESSURE DATA FROM IFA-431 AND IFA-432 . . . . A A-1

APPENDIX B: ESTIMATED CHANGES IN ROD INTERNAL VOLUME

OR GAS CONTENT FUEL DENSIFICATION $\quad \cdot \quad \cdot \quad \cdot \quad \cdot \quad \cdot \quad$ •

APPENDIX C: TEMPERATURE INPUT FOR GAS RELEASE CALCULATIONS • • • • C-1 


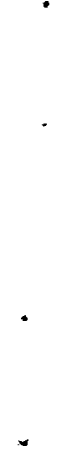

- 
FIGURES

1 Schematic of IFA-431/432 Fuel Rods with and Without Pressure Transducers

2 Schematic Diagram of the Pressure Measuring System Used in IFA-431 and IFA-432

3 Pressure Data from IFA-431/432 as a Function of the Moderator Temperature Prior to Initial Startup $\quad . \quad$. $\quad . \quad$. 9

4 Pressure Data From Test Assembly IFA-431 $\quad$ • . . . . . . . 11

5 The Average Linear Heat Generation Rate, Average Fuel

Centerline Temperature, and Internal Pressure as a

Function of Burnup for Rod 432-1 . $\quad . \quad$. . . . . . . 13

6 The Average Linear Heat Generation Rate, Average Fue 1

Centerline Temperature, and Internal Pressure as a

Function of Burnup for Rod 432-5 . $\quad$. $\quad$. . . . .

7 The Average Linear Heat Generation Rate, Average Fuel

Centerline Temperature, and Internal Pressure as a

Function of Burnup for Rod 432-6 . $\quad . \quad$. . . . . .

8 The Estimated Fission Gas Release Fraction as a

Function of Burnup for the IFA-432 Fuel Rods . . . . . 25

9 The Local Thermal Resistances as a Function of

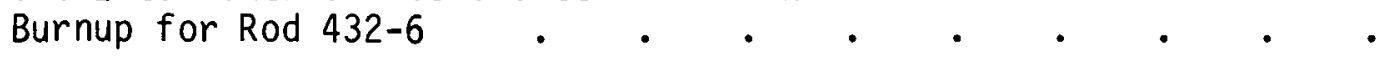

10 Comparison of the Estimated Gas Release Fractions

from Rod 432-1 to Those Predicted by GASREL,

FGASRL, and ANS54

11 Comparison of the Estimated Gas Release Fractions

from Rod 432-5 to Those Predicted by GASREL,

FGASRL, and ANS54

12 Comparison of the Estimated Gas Release Fractions from Rod 432-6 to Those Predicted by GASREL, FGASRL, and ANS54

13 A Relative Comparison of the Three Fission Gas Release Models . 36

C-1 Centerline Temperature Histories for Rods 432-1, 432-5, and 432-6 that were Used for Calculating Fission Gas Release 


\section{TABLES}

1. Halden Boiling Water Reactor Operating Data . . . . . . 3

2. Design Parameters and Instrumentation for IFA-431 and IFA-432 . 4

3. Free Volumes of Rods Containing Pressure Transducers . . . 6

4. Summary of the Estimated Pressure Drops $\quad . \quad \ldots \quad$. $\quad$. $\quad$. 19

A-1. Pressure Data From IFA-431 . . . . . . . . . . A-1

A-2. Pressure Data From IFA-432 . . . . . . . . . . A-4 


\section{INTRODUCTION}

The stored energy and gap conductance in a fuel rod during steady-state operation are important input parameters used to analyze postulated nuclear reactor accidents. A great deal of effort has been devoted to the development of steady-state fuel performance codes used to estimate the stored energy and gap conductance. Despite this level of effort, these codes contain some calculational uncertainties that are due to the difficulty involved in accurately modeling some of the complex phenomena that occur in a fuel rod. Specifically, it is difficult to model the effects of fission gas release, fuel densitification, and fuel relocation on the fuel-to-cladding gap conductance, and this difficulty is compounded by a lack of well-characterized data from fuel rods operating in the power ranges of commercial nuclear power plants.

In 1975, Pacific Northwest Laboratory (PNL) began a U.S. Nuclear Regulatory Commission (NRC)-sponsored program to provide well-characterized fuel rod data under normal operating conditions to assist the verification and development of steady-state fuel codes. Under this program, four instrumented fuel assemblies are being irradiated at the Halden Boiling Water Reactor in Norway. The pressure data from the first two of these assemblies are discussed in this report. Instrumented Fuel Assembly (IFA) 431 had a design power of $33 \mathrm{~kW} / \mathrm{m}$; its goal burnup of $37 \mathrm{GJ} / \mathrm{kgU}(4.3 \mathrm{GWd} / \mathrm{MTM})$ was reached in February 1976 . The second of these assemblies, IFA-432, has a design power of $49 \mathrm{~kW} / \mathrm{m}$; it has currently reached average rod burnups greater than $1700 \mathrm{GJ} / \mathrm{kgU}$ (20 GWd/MTM).

Three of the six fuel rods in each assembly were equipped with pressure transducers to monitor the internal fuel pressures that occur during irradiation. These data provide an excellent means for determining the time-dependent release of fission gases, which is an important concern in modeling fuel rod steady-state behavior. However, because both the internal void volume and temperature may also change with irrdiation, the absolute release fractions can be determined more accurately by direct measurement following irradiation. Thus, the purpose of this report is to provide an interim assessment of burnupdependent fission gas release from $\mathrm{UO}_{2}$ fuels to $1700 \mathrm{GJ} / \mathrm{kgU}(20 \mathrm{GWd} / \mathrm{MTM})$. A final assessment must await the results of the postirradiation examination, which may not be available for several years. 
A brief description of the experimental parameters and instrumentation is given in the next section. This is followed by graphics and written descriptions of the pressure data. The pressure data that have been obtained from both assemblies are tabulated in Appendix A. Finally, the data are discussed with emphasis on estimating fission gas release functions from the pressure measurements and comparing these results to the prediction from current fission gas release models. Appendix B contains the estimated changes in void volume and helium content which provide the bases for evaluating the initial pressure drops observed in the experimental data. The temperature histories used for calculating the fission gas release are given in Appendix $C$. 


\section{IRRADIATION TEST PARAMETERS AND INSTRUMENTATION}

\section{REACTOR OPERATION}

Test assemblies IFA-431 and IFA-432 were irradiated in different channels of the Halden Heavy Boiling Water Reactor (HBWR). The reactor is cooled by natural circulation of heavy water. It currently operates at a power level of $12 \mathrm{MW}$. The reactor operating data is shown in Table 1.

TABLE 1. Halden Boiling Water Reactor Operating Data

$\begin{array}{ll}\text { Power Leve } 1 & 12 \mathrm{MW} \\ \text { Reactor Pressure } & 3.45 \mathrm{MPa} \text { (500 psi) } \\ \text { Heavy Water Saturation Temperature } & 513 \mathrm{~K} \\ \text { Plenum Inlet Temperature } & 510 \mathrm{~K} \\ \text { Thermal Flux } & \sim 3 \times 10^{17} \mathrm{n} / \mathrm{m}^{2}-\mathrm{sec} \\ \text { Fast Flux ( }>1 \mathrm{MeV}) & \sim 5 \times 10^{15} \mathrm{n} / \mathrm{m}^{2}-\mathrm{sec} \\ \text { Average Fuel Power Density } & 14.8 \mathrm{~kW} / \mathrm{kg}\end{array}$

\section{ASSEMBLY DESCRIPTION}

The two instrumented nuclear fuel assemblies, IFA-431 and IFA-432, are essentially identical in design and each contain a cluster of six instrumented fuel rods. The experimental parameters include gap size, fuel density, fuel type (i.e., stable and unstable with respect to densification), and fill gas composition. The experimental parameters for the six fuel rods are listed in Table 2. Instrumentation for measuring neutron flux, fuel centerline temperatures at two locations, and cladding elongation was included in all rods; pressure transducers were included in rods 1,5 and 6 . A detailed description of the test design, precharacterization and fabrication of the assembly was reported by Hann et al., (1977). 
TABLE 2. Design Parameters and Instrumentation for IFA-431 and IFA-432

\begin{tabular}{|c|c|c|c|c|c|c|c|c|c|}
\hline \multirow[b]{2}{*}{$\begin{array}{l}\text { Rod } \\
\text { No. }\end{array}$} & \multirow{2}{*}{\multicolumn{2}{|c|}{$\begin{array}{c}\text { Cold } \\
\text { Diametrical Gap }\end{array}$}} & \multirow[b]{2}{*}{$\begin{array}{l}\text { Fill } \\
\text { Gas }\end{array}$} & \multirow{2}{*}{$\begin{array}{l}\text { Fuel } \\
\text { Density } \\
\text { \% TD }\end{array}$} & \multirow[b]{2}{*}{$\begin{array}{l}\text { Fuel } \\
\text { Type (a) }\end{array}$} & \multicolumn{4}{|c|}{ Instrumentation } \\
\hline & & & & & & Temp & ture & Preccuro & Cladding \\
\hline 1 & 0.229 & 9 & $\mathrm{He}$ & 95 & Stable & $T C^{(b)}$ & $T C$ & $P T(c)$ & $F C(d)$ \\
\hline 2 & 0.381 & 15 & $\mathrm{He}$ & 95 & Stable & $T C$ or $U T^{(e)}$ & $T C$ & PI. & ES \\
\hline 3 & 0.076 & 3 & $\mathrm{He}$ & 95 & Stable & $T C$ & $T C$ & - & ES \\
\hline 4 & 0.229 & 9 & $\mathrm{Xe}$ & 95 & Stable & $T C$ & TC & -- & ES \\
\hline 5 & 0.229 & 9 & $\mathrm{He}$ & 92 & Stable & $T C$ & $T C$ & PT & ES \\
\hline 6 & 0.229 & 9 & $\mathrm{He}$ & 92 & Unstable & TC & $T C$ & PT & ES \\
\hline
\end{tabular}

(a) with respect to densification

(b) thermocouple

(c) pressure transducer

(d) elongation sensor

(e) ultrasonic thermometer in IFA-432

The rods that were instrumented with the pressure transducers $(1,5$, and 6) had a cold diametrical gap of $0.229 \mathrm{~mm}$ and were backfilled with helium gas at atmospheric pressure. These rods were designed to evaluate the effects of fuel density and stability. Rod 1 contained a stable fuel with 95\% theoretical density (TD). Both of the other rods contained 92\% TD fuel; but the fuel in rod 6 was unstable (i.e., susceptible to densification). Thus, the effects of fuel density and fuel stability can be evaluated by comparing the data from rods 1 and 5 and rods 5 and 6 , respectively.

Figure 1 is a schematic of the fuel rod design. Each fuel rod contains 45 fuel pellets with a nominal diameter of $10.7 \mathrm{~mm}$ and a nominal length of $12.7 \mathrm{~mm}$. The pellets have flat ends and were fabricated by compacting and sintering $\mathrm{UO}_{2}$ powder to the required density. All fuel pellets were enriched to $10 \mathrm{wt} \%{ }^{235} \mathrm{U}$. Dysprosium oxide pellets were located at each end of the fuel column and a helical spring was used to keep the fuel stack compact. The pellets at each end of the fuel stack were drilled to accommodate the centerline thermocouples. All rods were clad with annealed, seamless Zircaloy-2 that had an outer diameter of $12.789 \mathrm{~mm}$ and an inner diameter of $10.909 \mathrm{~mm}$.

The fuel rods were designed to minimize the internal free volume and thereby maximize the response to variations in the pressure. The asfabricated free volumes for the six rods containing pressure transducers are 


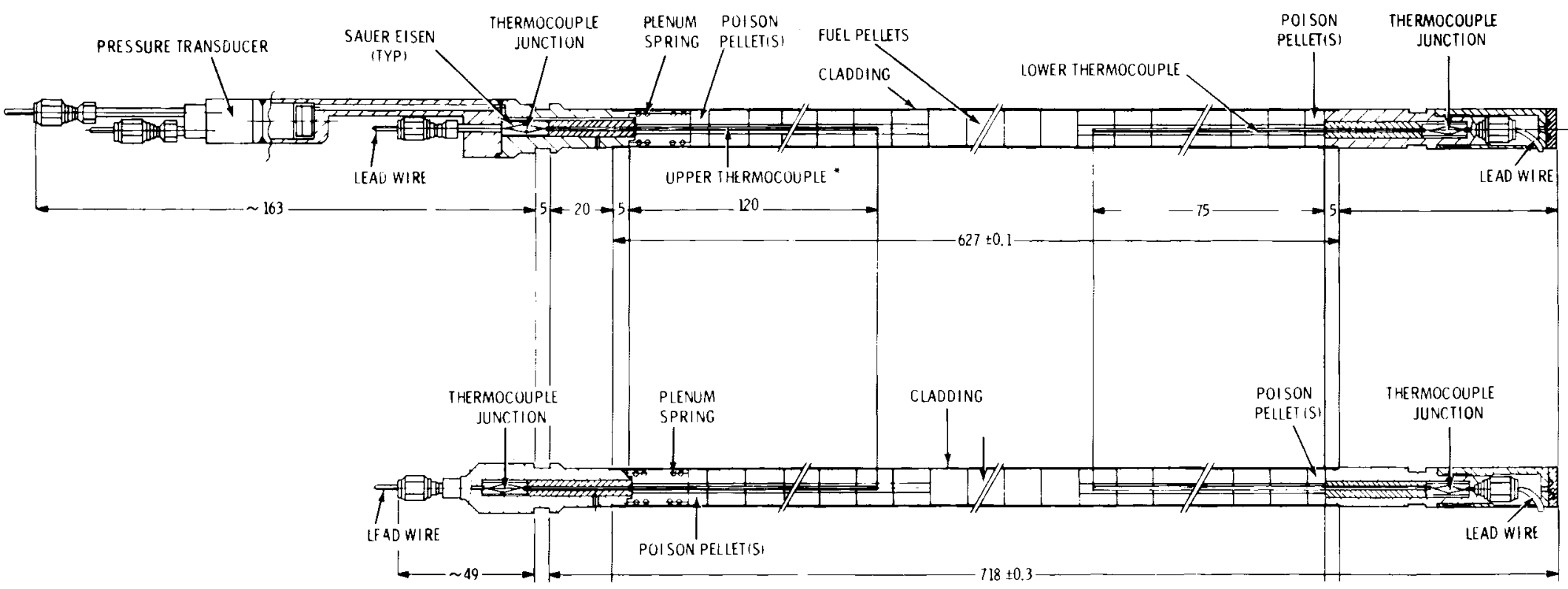

FIGURE 1. Schematic of IFA-431/432 Fuel Rods With and Without Pressure Transducers (a11 dimensions in $\mathrm{mm}$ ) 
listed in Table 3. These volumes were calculated from geometrical measurements of the individual fuel pellets and the assembled fuel rods. The plenum and total volumes include the estimated volume of the pressure transducers.

TABLE 3. Free Volumes(a) of Rods Containing Pressure Transducers

$\begin{array}{lccc}\text { Rod Number } & \begin{array}{c}\text { Plenum }(b) \\ \text { Volume, } \\ \mathrm{cm}^{3}\end{array} & \begin{array}{c}\text { Free Volume } \\ \text { Around Fuel } \\ \text { Column, } \mathrm{cm}^{3}\end{array} & \begin{array}{c}\text { Total Free Volume } \\ \text { of Fuel Rods, } \\ \mathrm{cm}^{3}\end{array} \\ \text { IFA-431-1 } & 2.5 & 2.6 & 5.1 \\ \text { IFA-431-5 } & 1.9 & 2.3 & 4.2 \\ \text { IFA-431-6 } & 1.6 & 2.5 & 4.1 \\ \text { IFA-432-1 } & 2.0 & 2.5 & 4.5 \\ \text { IFA-432-5 } & 2.0 & 2.5 & 4.5 \\ \text { IFA-432-6 } & 2.2 & 2.5 & 4.7\end{array}$

(a) As fabricated.

(b) Includes estimated volume of pressure transducer, $\sim 0.4 \mathrm{~cm}^{3}$.

\section{PRESSURE INSTRUMENTATION}

Rods 1,5 , and 6 in both assemblies were instrumented with null-balance type pressure transducers. A schematic of the transducer and the pressure measuring system is shown in Figure 2. The sensing mechanism in the pressure transducer is a thin platinum membrane that is exposed to the internal rod gas on one side and the externally controlled helium gas on the other. The pressure balance across the membrane is indicated when an electrical circuit is closed between the membrane and a contact point.

Pressure measurements are made by manually pressurizing the controlled helium gas to about $0.1 \mathrm{MPa}(1 \mathrm{~atm})$ above the highest pressure of the rods that are connected to the manifold and thereby opens the electrical circuit. The external pressure is then slowly released until the electrical circuit closes. This external pressure is used to determine the internal pressure. The pressure balance can be determined automatically by the computer or manually by an operator. The accuracy of the system is reported to be $\pm 0.02 \mathrm{MPa}$. 


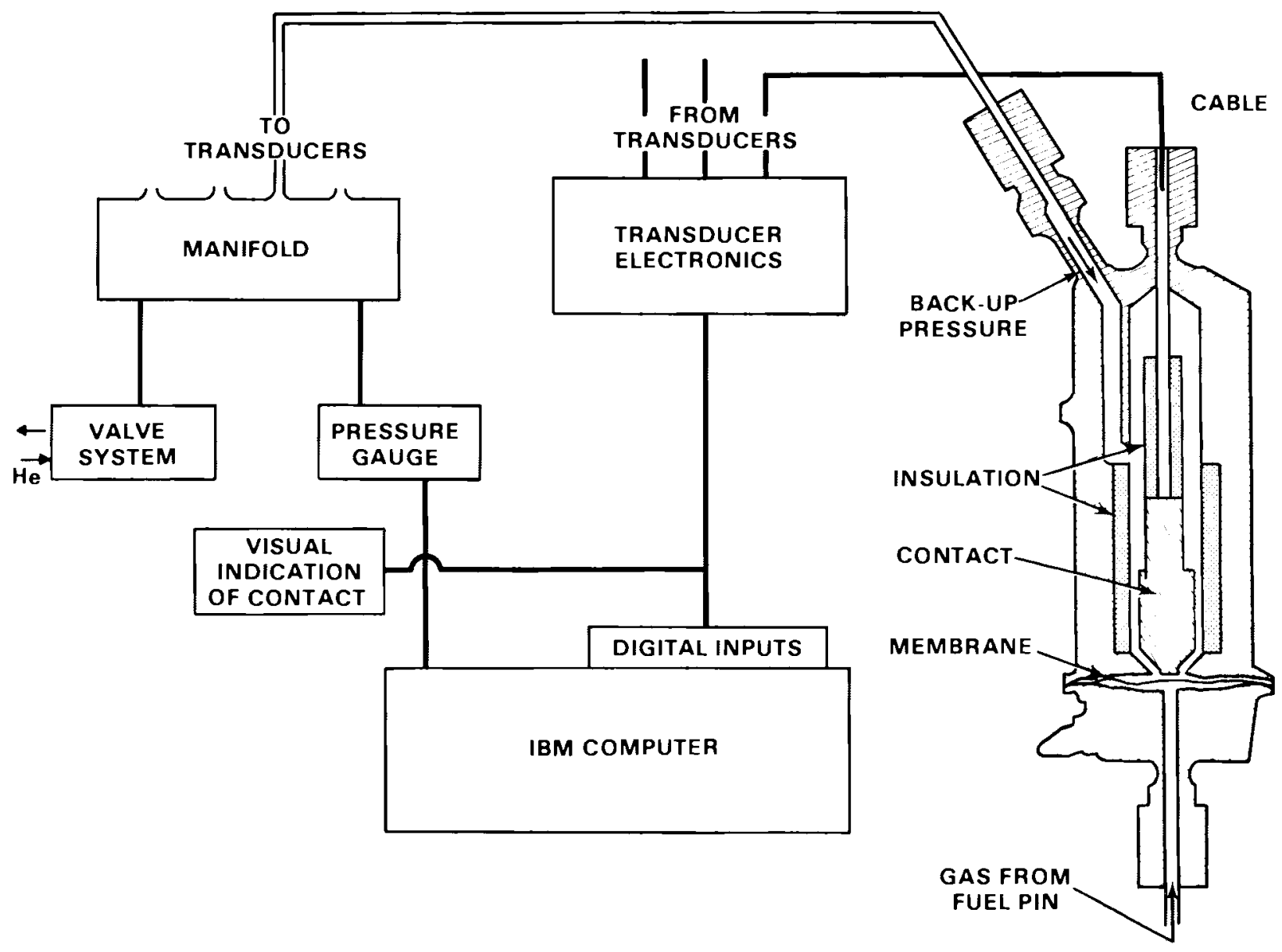

FIGURE 2. Schematic Diagram of the Pressure Measuring System Used in IFA-431 and IFA-432 



\section{EXPERIMENTAL RESULTS}

The pressure measurements were taken manually at intervals varying from a few hours to several days. All of the pressure data from the two assemblies is tabulated in Appendix A, Tables A-1 and A-2. The moderator temperatures and the assembly and reactor power levels at the time of the measurements are also included in the tables.

Prior to the initial startup of the assemblies, the moderator was heated externally. The pressure data during these periods as a function of the moderator temperature is shown in Figure 3. The solid line represents the calculated temperature dependence at constant volume and gas content.

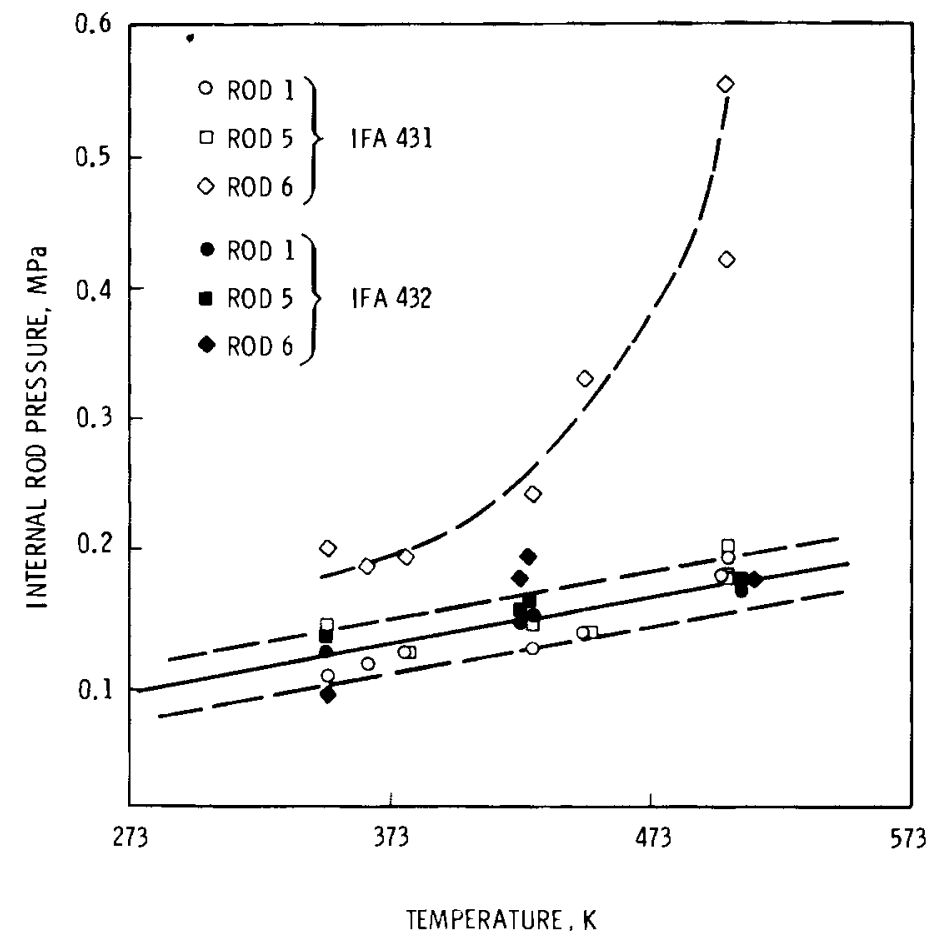

FIGURE 3. Pressure Data from IFA-431/432 as a Function of the Moderator Temperature Prior to Initial Startup 
With the exception of Rod 431-6, all of the pressure data is in reasonable agreement with the calculated temperature dependence. There are some indications in the other five rods of sorbed gas being released during the heatup but the measured pressures do not greatly exceed the expected uncertainty in the measurements. In contrast, the pressure measurements from Rod 431-6 are higher than expected at all temperatures. The ratio of the measured to the expected pressures range from $\sim 1.5$ at low temperatures $(<373 \mathrm{~K})$ to $\sim 3$ at $498 \mathrm{~K}$. These ratios greatly exceed the estimated uncertainty in the measurements and suggest either a faulty pressure transducer or a large sorbed gas release in this rod.

The pressure data as a function of burnup will be presented separately for the two assemblies in the following sections.

PRESSURE DATA FROM IFA-431

The internal gas pressures for the three IFA-431 rods as a function of burnup at full $(95 \pm 10 \mathrm{~kW})$ and low assembly power are shown in Figure 4 . At the low power level, the moderator temperature was $499+5 \mathrm{~K}$ for all of the measurements and about $10 \mathrm{~K}$ higher at full power. The vertical line at $215 \mathrm{GJ} / \mathrm{kgM}$ (2.5 GWd/MTM) in Figure 4 indicates the position of a scheduled reactor shutdown ( 2 months) for refueling and maintenance.

The data from Rods 431-1 and 431-5 show similar behaviors. This is especially true at low power levels where the pressure decreases rapidly during the first $17 \mathrm{GJ} / \mathrm{kgU}$ (0.2 GWd/MTM) and remains relatively constant thereafter. The magnitude of the pressure drop is greater in Rod 431-1 than in Rod 431-5 and the stable pressure in Rod 431-1 approaches the minimum measurable pressure, i.e., $0.1 \mathrm{MPa}$.

At full reactor power, the pressure decreases continuously with burnup until the long reactor shutdown occurs. The magnitude of the decrease is greater in Rod 431-1 than in Rod 431-5. An increase in pressure is observed in both rods immediately following the long outage. The pressures then rapidly decrease to values consistent with the previous pressure measurements. The pressure transducer in Rod 431-1 failed shortly thereafter. 

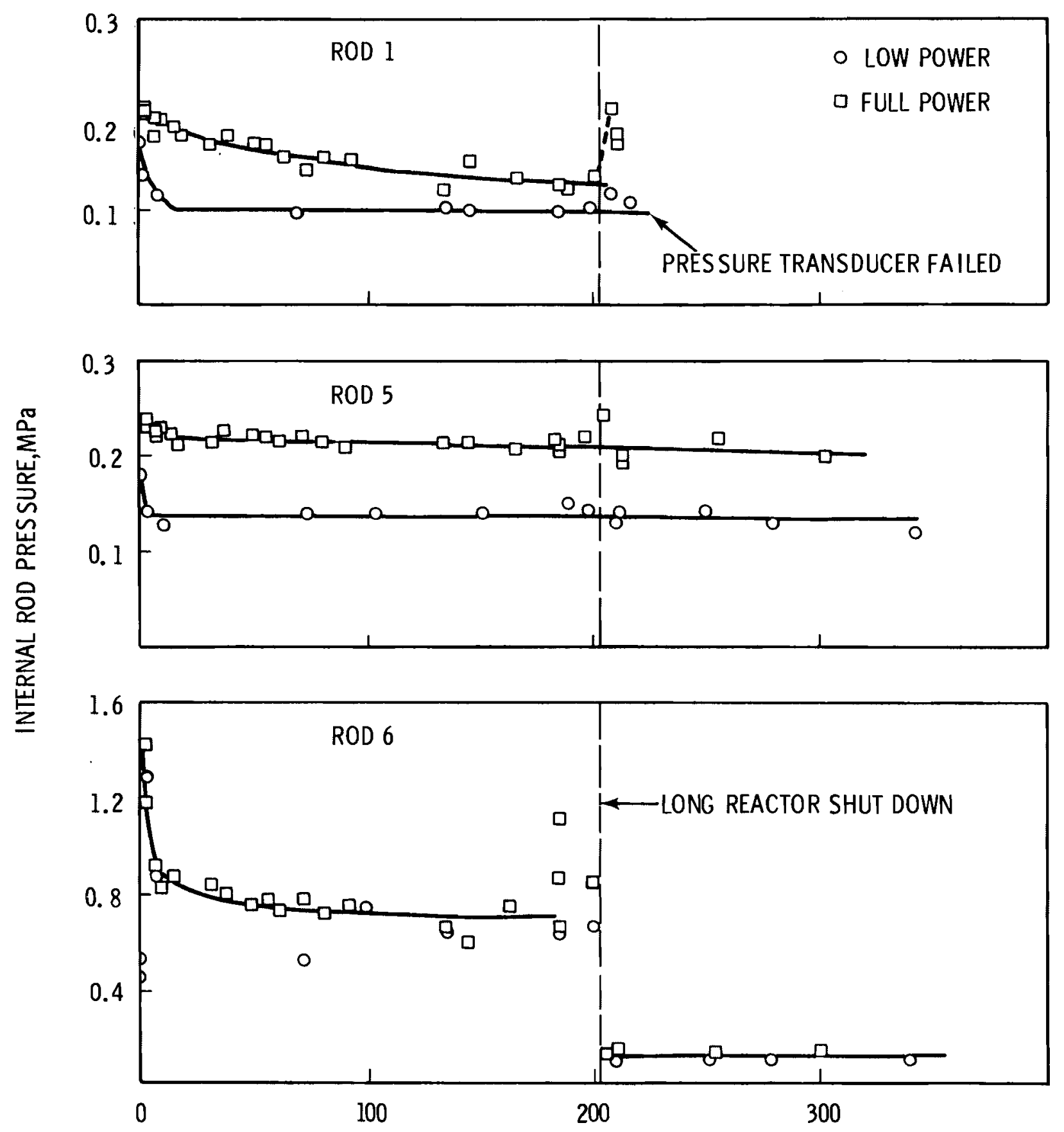

AVERAGE ROD BURNUP, GJ/kgU

FIGURE 4. Pressure Data From Test Assembly IFA-431 
The measured gas pressures in Rod 431-6 are significantly different than in Rods 431-1 and 431-5 with respect to both the magnitude of the pressure (up to 7 times greater) and the variation of pressure with burnup as illustrated in Figure 4. A large pressure increase is observed during and after the initial rise to power. This is followed by a rapid pressure decrease at $\sim 8 \mathrm{GJ} / \mathrm{kgU}$ $(0.1 \mathrm{GWd} / \mathrm{MTM})$ and a more gradual decrease in pressure until the long reactor outage. Following the outage, the pressures measured at low power dropped to the minimum pressure that could be measured experimentally and the pressures measured at full reactor power were only slightly above this minimum.

There is greater scatter in the pressure measurements from Rod 431-6 than in measurements from either Rod 431-1 or 431-5. This is especially evident at 190 GJ/kgU (2.2 GWd/MTM) where a difference of $0.4 \mathrm{MPa}$ exists in the pressures measured at full reactor power. Another unique feature of the data from Rod 431-6 is that in many cases there is no significant difference between pressures measured at low power and full reactor power.

\section{PRESSURE DATA FROM IFA-432}

The burnup dependence of the internal rod pressures is shown in Figures 5 , 6 , and 7 , for Rods $432-1,432-5$, and $432-6$, respectively. The pressure data was taken at zero or low reactor power levels to minimize the effects of large temperature gradients; the moderator temperature was $510 \pm 5 K$. The average steady-state centerline temperatures and linear heat generation rates at the upper and lower thermocouple locations during full power reactor operation are also included in the figures.

The data from all three rods shows a pressure decrease with burnup until 200 to $300 \mathrm{GJ} / \mathrm{kgU}(2.3$ to $3.5 \mathrm{GWd} / \mathrm{MTM})$ is reached, which represents an incubation period for fission gas release. The end of the incubation period is characterized by an increase in lower thermocouple temperatures and internal pressures. The fuel temperature at the lower thermocouple position continues to $r$ ise for a period and then stabilizes. The temperature increase at the upper thermocouple position is delayed with respect to the lower position and each upper thermocouple failed shortly after the temperatures began to increase 

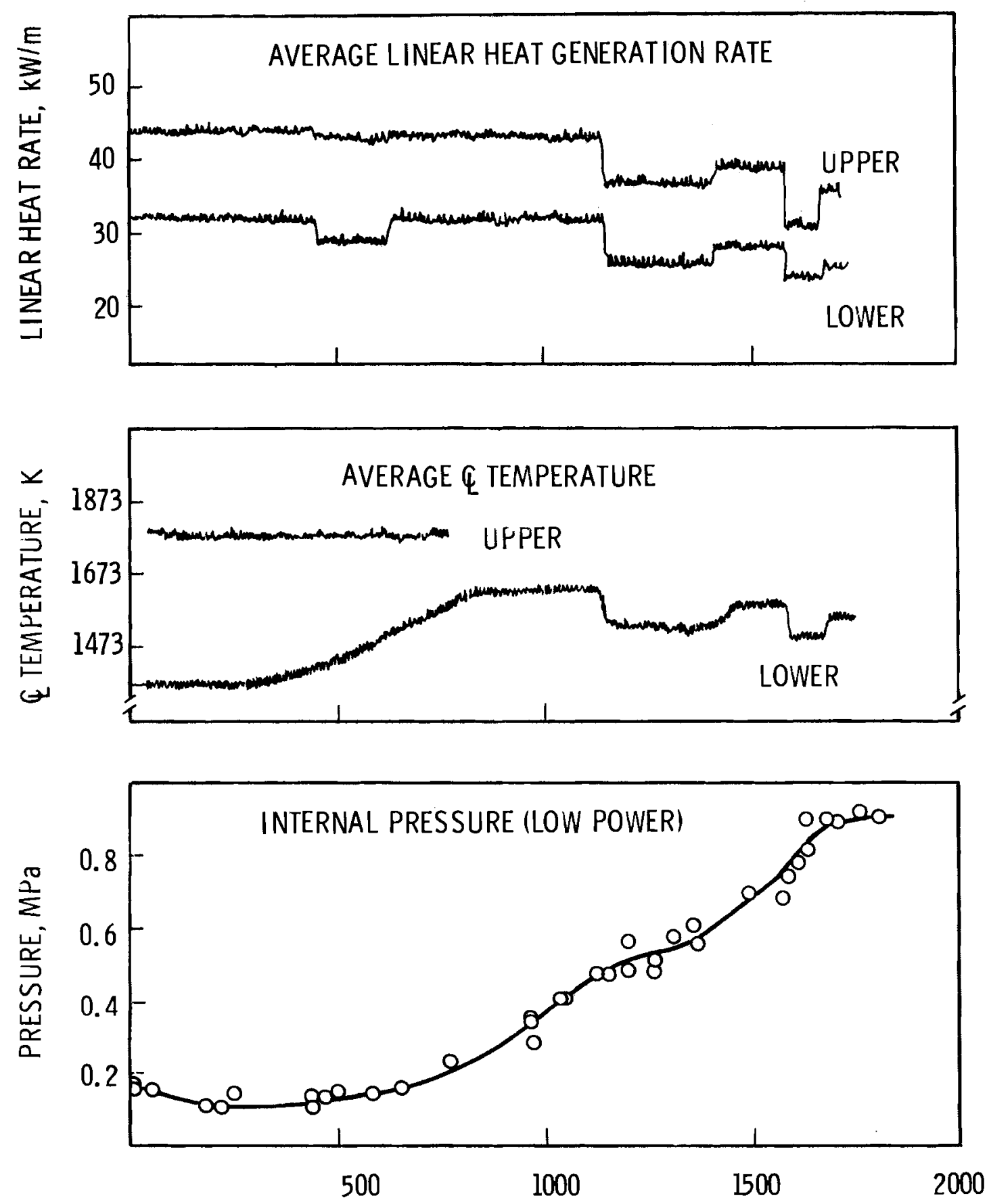

\section{AVERAGE BURNUP GJ $/ \mathrm{kgU}$}

FIGURE 5. The Average Linear Heat Generation Rate, Average Fuel Centerline Temperature, and Internal Pressure as a Function of Burnup for Rod 432-1 

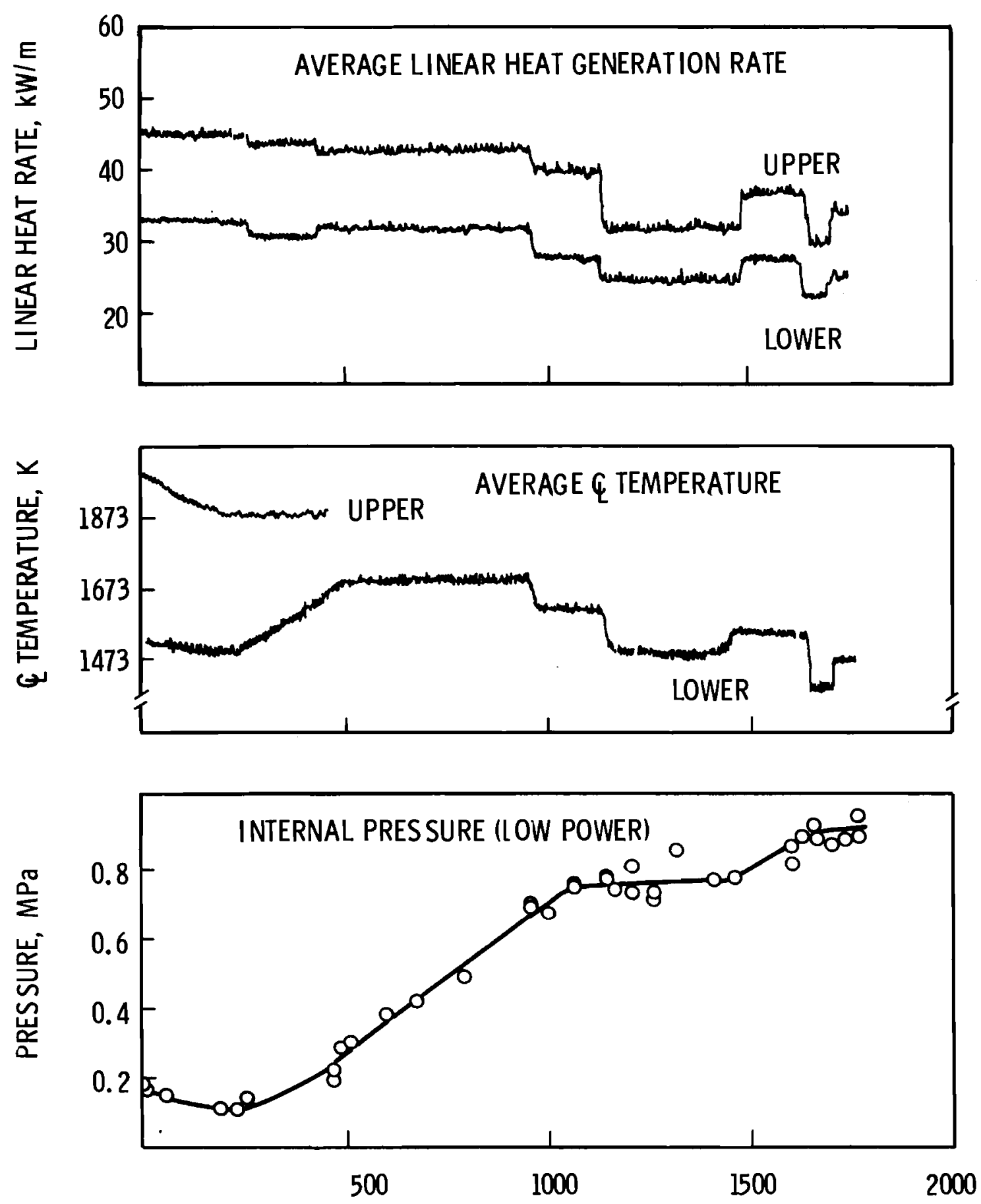

\section{AVERAGE BURNUP, GJ/kgU}

FIGURE 6. The Average Linear Heat Generation Rate, Average Fue 1 Centerline Temperature, and Internal Pressure as a Function of Burnup for Rod 432-5 
ROD 432-6
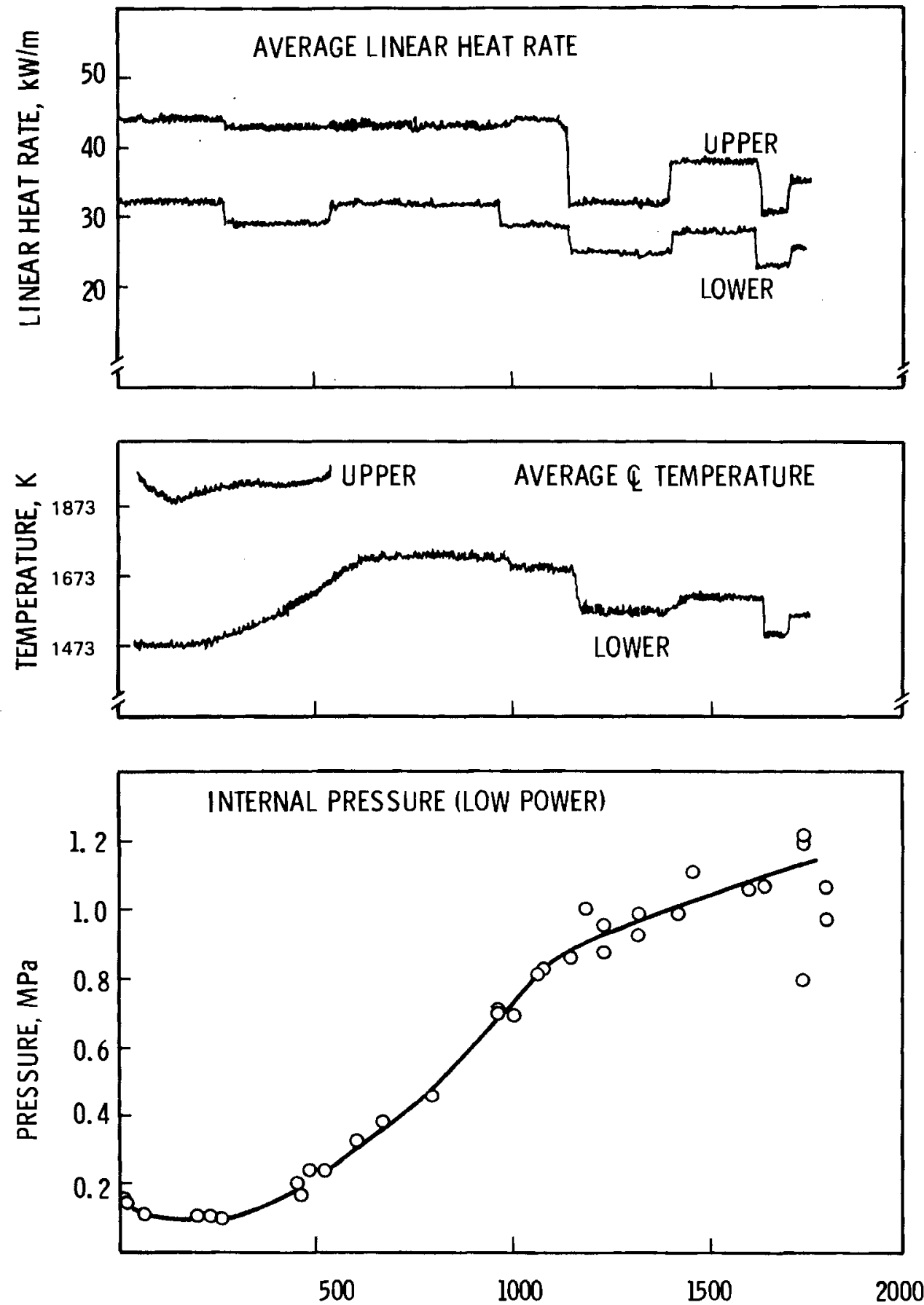

AVERAGE BURNUP, GJ/kgU

FIGURE 7. The Average Linear Heat Generation Rate, Average Fue 1 Centerline Temperature, and Internal Pressure as a Function of Burnup for Rod 432-6 
at its location. During the period of increasing fuel temperatures, the internal pressures increased at a fairly constant rate until about 1000 to $1200 \mathrm{GJ} / \mathrm{kgU}$ (12 to $14 \mathrm{GWd} / \mathrm{MTM}$ ) where lower fuel temperatures resulted in lower fission gas release. At higher burnups, the pressure changes generally correspond to the respective changes in the fuel temperatures.

The temperatures in Rod 432-1 were about 100K lower than Rod 432-5 unti 1 $\sim 1100 \mathrm{GJ} / \mathrm{kgU}$ (13 GWd/MTM) and about 50K higher thereafter. These temperature differences are also reflected in the pressure data where Rod 432-1 shows a longer incubation period and a lower gas release rate up to $1100 \mathrm{GJ} / \mathrm{kgU}$ and a higher gas release rate thereafter. Consequently, the same internal pressure $(0.95 \mathrm{MPa})$ at low reactor power existed in both rods at $1700 \mathrm{GJ} / \mathrm{kgU}$ (20 GWd/MTM). By comparison, Rod 432-6 operated at higher temperatures throughout the irradiation period and the internal pressure at low reactor power was $1.2 \mathrm{MPa}$ at $1700 \mathrm{GJ} / \mathrm{kgU}$.

The pressure data obtained at full reactor power shows the same general trends as the low power data but with somewhat more scatter. The maximum pressures thus far recorded are 1.32, 1.66, and $2.01 \mathrm{MPa}$, respectively, for Rods 1 , 5 and 6 , IFA-432. 


\section{$\underline{\text { DISCUSSION }}$}

Features regarding the pressure data that are particularly important include the abnormally high pressures observed in Rod 431-6, the initial pressure drop in the remaining five rods, and fission gas release as estimated from the internal pressure data. Each of these will be discussed individually in the following sections.

PRESSURE DATA FROM IFA-431, ROD 6

The abnormally high pressures measured for Rod 431-6 could be due to either sorbed gas release or a faulty pressure transducer. The gas necessary to achieve the pressures indicated after the first rise to power is about four times the amount released during analysis of the fuel following fabrication at 1873K (Hann et al., 1977). This, and the fact that Rod 432-6, which contained the same type of fuel, did not exhibit large sorbed gas releases indicates the fuel type was not responsible for the abnormal behavior.

The fuel pellets from all IFA-431 rods were outgassed in air at 398K for 20 hours just prior to loading and could have adsorbed some gases during this treatment. However, moisture analysis after outgassing showed only $0.3 \mathrm{ppm}$ $\mathrm{H}_{2} \mathrm{O}$ for the Rod 431-6 fuel, which is inconsistent with large gas pickups. Furthermore, the fuels in Rods 431-1 and 431-5 showed no significant sorbed gas releases even though they had received the same outgassing treatment. Consequently, it appears a faulty pressure transducer is responsible for the high pressure readings in Rod 431-6.

The characteristics of the pressure data give additional support for a faulty pressure transducer. First, there was a large amount of scatter in the data that was not observed in the other rods. Also, for many of the measurements, there was no difference between the pressures measured at low reactor power and those measured at full power. The pressure at full power should have been greater than 50 percent higher due to the increased temperature and thermal expansion of the fuel, which reduces the available free volume. Finally, no other mechanism could easily be linked to the large pressure drop following 
the long reactor shutdown. The low pressures measured during the second reactor cycle concur with the measured gas content in Rod 431-6 following irradiation (Hann et al., 1979). This suggests that the transducer may have been operating correctly during the second cycle; however, we can offer no explanation for its original performance. In any event, we have concluded that the high pressures in Rod 431-6 were due to a faulty pressure transducer; this data warrants no futher discussion.

\section{INITIAL PRESSURE DROPS IN REMAINING RODS}

The magnitude of the pressure drops during the initial stages of irradiation was $0.06 \mathrm{MPa}$ for all rods except 431-5; during the initial stages, its pressure decreased $\sim 0.03 \mathrm{MPa}$. These pressure decreases could be due to an increase in the free volume within the fuel rod and/or a decrease in the gaseous helium content. There are mechanisms that could be responsible for these changes: 1) fuel densification, 2) fuel cracking to expose internal porosity, 3) helium absorption by the $\mathrm{UO}_{2}, 4$ ) irradiation-induced entrapment and 5) helium leakage from the fuel rod. The observed pressure drops could be caused by one of these mechanisms or several acting simultaneously. Therefore, we have estimated the maximum expected contribution from each in an attempt to identify the appropriate mechanisms. The results are summarized in Table 4, and the basis for the estimates is given in Appendix B.

Fuel densification is the predominant mechanism for increasing the free volume and, for the unstable fuel type in Rod 432-6, its expected contribution approximates the observed pressure drop. For the other four rods, which contain stable fuel types, densification accounts for only 10 to 27 percent of the observed pressure drops. The estimated densification in these rods was based on resintering results (Hann et al., 1977) and has not been experimentally verified under irradiation conditions. Thus, the effects of densification in these rods may be underestimated. However, since the final density for the 95\% TD fuels in Rods 431-1 and 432-1 would exceed the theoretical density if densification were the sole contributor to the initial pressure drops, fuel densification can not be totally responsible. 
TABLE 4. Summary of the Estimated Pressure Drops

\begin{tabular}{|c|c|c|c|c|c|c|}
\hline \multirow[b]{2}{*}{$\begin{array}{l}\text { Rod } \\
\text { Number }\end{array}$} & \multicolumn{6}{|c|}{ Estimated Pressure Urops (MPa) } \\
\hline & $\begin{array}{c}\text { Fuel } \\
\text { Densification }\end{array}$ & $\begin{array}{c}\text { Fue } 1 \\
\text { Cracking } \\
\end{array}$ & $\begin{array}{c}\text { Helium } \\
\text { Absorption }\end{array}$ & $\begin{array}{c}\text { Irradiation } \\
\text { Induced } \\
\text { Entrapment }\end{array}$ & $\begin{array}{l}\text { Total Estimated } \\
\text { Pressure Drop }\end{array}$ & $\begin{array}{c}\text { Measured } \\
\text { Pressure Drop }\end{array}$ \\
\hline$\overline{431-1}$ & 0.008 & $<0.001$ & 0.011 & 0.002 & 0.022 & 0.060 \\
\hline $431-5$ & 0.009 & 0.003 & 0.013 & 0.002 & 0.027 & 0.030 \\
\hline $432-1$ & 0.009 & $<0.001$ & 0.012 & 0.022 & 0.044 & 0.060 \\
\hline $432-5$ & 0.009 & 0.003 & 0.012 & 0.022 & 0.046 & 0.060 \\
\hline $432-6$ & 0.058 & $<0.001$ & 0.012 & 0.022 & 0.093 & 0.060 \\
\hline
\end{tabular}

The part fuel cracking plays in increasing the internal free volumes is small and is not considered to be an important factor in changing the internal pressures. This is especially true if the internal pores contain gases. Under these conditions, the contributions from cracking would be less than those given in Table 4, and if the internal gas pressures exceed $0.1 \mathrm{MPa}$, a pressure increase rather than a decrease would result from fuel cracking.

Because increases in the free volumes cannot account for the observed pressure drops, consideration must also be given to the mechanisms for helium losses from the internal rod gas. The absorption of helium into the fuel potentially can cause the removal of helium from the gas phase. Corresponding estimated pressure drops account for $18 \%$ to $43 \%$ of the observed pressure drops. The estimates shown in Table 4 were based on experimental data obtained from fine powders heated to $1473 \mathrm{~K}$. Solid fuel pellets would be expected to absorb less gas. Thus, the pressure drops given in Table 4 represent an upper 1 imit of helium that could be absorbed and, even so, cannot account for the observed pressure drops.

The irradiation-induced entrapment of xenon in $\mathrm{UO}_{2}$ fuels has been observed experimentally, and helium is expected to behave similarly. Because no experimental data regarding the entrapment of helium could be located, the estimated pressure drops in Table 4 were based on data for xenon entrapment. Thus, the estimated pressure drops may not be directly applicable. However, the linear decrease in pressure with increasing burnup that would be expected 
for irradiation-induced entrapment was not observed experimentally. The minimum pressures occurred at $\sim 17 \mathrm{GJ} / \mathrm{kgU}(0.2 \mathrm{GWd} / \mathrm{MTM})$ for the rods in IFA-431, whereas exposures of $\sim 170 \mathrm{GJ} / \mathrm{kgU}(2.0 \mathrm{GWd} / \mathrm{MTM})$ were required to achieve the minimum pressure in the IFA-432 rods. Also, the largest fraction of the pressure drop in each of the IFA-431 rods occurred during the first irradiation day, which is inconsistent with the expected behavior for irradiation entrapment. Therefore, irradiation-induced entrapment does not appear to be the mechanism responsible for the pressure drops.

Except for Rod 432-6, the above mechanisms cannot account for the observed pressure drops, even when their combined contributions are considered. This implies that densification is greater than expected in the stable fuel types and/or helium is being lost by some other mechanism. The amount of helium lost can be estimated from the results of the postirradiation examination conducted on Rod 431-6. This rod was found to contain $3.33 \mathrm{ml}$ NDT of gas: $85 \%$ of it being helium. This amounts to less than $70 \%$ of the helium calculated to be present initially in the fuel rod. The corresponding pressure drop caused by this loss of helium is from 0.046 to $0.052 \mathrm{MPa}$ for the IFA 431 and 432 fuel rod designs. This is greater than $75 \%$ of the observed pressure drops, suggesting that helium loss is the predominant cause of the initial pressure drops.

Neither helium absorption or entrapment can account for the observed pressure drops; therefore, it is essential to consider helium leakage from the fuel rods. Because all fuel rods showed the initial pressure drops, helium loss caused by leakage must be associated with the rod design rather than a defective weld or manufacturing defect. The fuel rods all contained two centerline thermocouples and the junctions between the thermocouples and lead wires are the most logical sites for helium leaks. They consist of a glass bead at the end of the lead wire and a sauereisen(a) plug between the lead wire and the thermocouple. Thus, helium leakage requires diffusion or effusion through the sauereisen plug and a poor glass-to-metal seal at the end of the lead wire. Under these conditions, helium would leak into the lead wire until the available volume was consumed. This type of behavior has been observed

(a) An inorganic cement used for insulating thermocouples. 
experimentally in out-of-reactor tests at Halden, but only when the glass beads at the end of the lead wires were cracked. Thus, although it is difficult to determine whether cracks exist in these thermocouple junctions, cracking would be necessary in at least one of the junctions for this to be a viable mechanism for the pressure drops.

In summary, none of the mechanisms examined give a completely satisfactory explanation for the pressure drops observed during the initial stages of irradiation. Helium loss is believed to be the predominant factor for the fuel rods with stable fuel types, and the postirradition examination of IFA-432 should provide a check for this. The mechanisms for the helium loss are difficult to assess, but based on the available information we feel that helium leakage into the thermocouple lead wires provides the best explanation.

\section{FISSION GAS RELEASE}

The internal pressure measurements from IFA-431, rods 1 and 5 , show no evidence of fission gas release. The pressures at low reactor power decrease initially and then remain constant throughout the remainder of the irradiation life. We can estimate an upper boundary for fission gas release by calculating the gas release necessary to obtain a measurable pressure increase, $0.02 \mathrm{MPa}$ $(0.2 \mathrm{~atm})$. For the fuel rods used in these tests, the required release fraction at end of life is estimated to be $0.8 \%$ and represents an upper limit for the fission gas release since pressure increases were not observed.

The peak centerline fuel temperatures were approximately $1473 \mathrm{~K}$ and $1523 \mathrm{~K}$, respectively, for Rods 431-1 and 431-5. These temperatures are sufficiently low that the estimated upper limit for gas release is reasonable. The gas content of these two rods was not measured following irradiation; fission gas release for Rod 431-6, however, was found to be $\sim 0.25 \%$ (Hann et al., 1979). Since all three rods had similar temperature histories, it is reasonable to assume similar release fractions for Rods 431-1 and 431-5. 
In contrast to IFA-431, the pressure data from IFA-432 shows fission gas release beyond about $250 \mathrm{GJ} / \mathrm{kgU}$ ( $3 \mathrm{GWd} / \mathrm{MTM}$ ). Fuel temperature is the predominant factor influencing gas release, and the difference in the gas release characteristics of the two assemblies can be attributed to the higher fuel temperatures ( $>1773 \mathrm{~K}$ peak centerline) in the fuel rods from IFA-432. The importance of temperature on gas release is also indicated by the lower temperatures and pressure increases in Rod 432-1 than in Rods 432-5 and 432-6 during the initial $1000 \mathrm{GJ} / \mathrm{kgU}$ (12 GWd/MTM) exposure. Also, the direct correlation between the pressure and temperature changes suggests a strong connection between temperatures and gas release.

Calculating the fission gas release fractions from the pressure data requires the following: gas temperature, internal volume of the fuel rod, and helium content. All of these variables could change with irradiation. Thus, rather large uncertainties exist in the absolute value of the calculated release fractions. Some of these uncertainties can be minimized by considering the conditions that exist at the time measurements are taken and by making assumptions regarding the changes in the fuel during irradiation. However, the effects of the assumptions on the calculated release fractions must also be considered and will be briefly discussed below.

The uncertainty due to temperature can be minimized by using the pressure data taken at zero or low reactor power. Under these conditions, the large temperature gradients along the fuel column are minimized and therefore the gas temperature can be assumed equal to the moderator temperature. This assumption underestimates the actual gas temperature and, therefore, the calculated release fractions would be higher than the true value. The error introduced by this assumption would be less than $10 \%$.

As discussed previously, the initial drop in pressure could be due to either an increase in free volume or a decrease in the helium content. Also, relative contributions of these factors cannot be determined with the available information. However, we can calculate a range of gas release fractions by assuming the pressure drop is totally due to either one or the other. For 
the stable fuel types, the actual release fractions are expected to be closer to the calculation for helium loss while for the unstable fuel, Rod 432-6, the calculation based on a volume increase is more appropriate.

Additional assumptions regarding the internal volume and helium content are as follows:

- the internal free volume remains constant after $250 \mathrm{GJ} / \mathrm{kgU}$,

- the helium content remains constant after $250 \mathrm{GJ} / \mathrm{kgU}$,

- the fission gas release fraction at $250 \mathrm{GJ} / \mathrm{kgU}$ equals 0.01 .

The first assumption requires densification to be complete at $250 \mathrm{GJ} / \mathrm{kgU}$ and neglects the effects of irradiation-induced swelling on the internal volume. Densification has been reported to be completed at burnup levels <100 GJ/kgU (1.2 GWd/MTM) (Freshley et al., 1976) and the postirradiation examination of Rod 431-6 (Hann et al., 1979) shows densification was completed before $350 \mathrm{GJ} / \mathrm{kgU}$ ( $4 \mathrm{GWd} / \mathrm{MTM}$ ). Therefore, this assumption primarily affects the calculated release fraction by neglecting fuel swelling and its effect on the internal free volumes. Fuel swelling would decrease the internal free volume and, therefore, the fission gas release fraction is overestimated as a result of this assumption. The effect would increase with burnup, and at $1700 \mathrm{GJ} / \mathrm{kgU}$ (20 GWd/MTM) the error could range from 5\% to $20 \%$ depending on the swelling model used and the initial free volume of the fuel rod.

The remaining two assumptions deal with the helium content in the gas phase. The effects of these assumptions on the calculated release fractions are predominant during the early stages of irradiation. Additional loss of helium from the gas after $250 \mathrm{GJ} / \mathrm{kgU}$ ( $3 \mathrm{GWd} / \mathrm{MTM}$ ) or a higher release fraction at $250 \mathrm{GJ} / \mathrm{kgU}$ would cause the release fractions to be underestimated. The magnitude of the error decreases as burnup increases. For example, a 100\% error in the assumed release fraction at $250 \mathrm{GJ} / \mathrm{kgU}$ would produce less than a $2 \%$ error in the calculated release fractions at $1700 \mathrm{GJ} / \mathrm{kgU}$. Also, the maximum error in the calculated release fractions would occur if all of the helium was lost from the system and even for this unlikely condition, the error would be less than $10 \%$ at $1700 \mathrm{GJ} / \mathrm{kgU}$.

There was no significant evidence in the pressure data of helium loss following $250 \mathrm{GJ} / \mathrm{kgU}$. Also, the fairly constant fuel temperatures during the 
initial irradiation are in accordance with the assumed gas release fraction. Therefore, we feel that calculations based on the above assumptions would lead to reasonable, but somewhat high, estimates of the actual fission gas release fractions.

Figure 8 shows the calculated gas release ranges as a function of burnup for Rods 432-1, 432-5, and 432-6. The calculations were based on the above assumptions and a fission gas production rate of 0.3 atoms/fission. The lower boundaries are calculated by assuming that helium loss is responsible for the initial pressure drops while the assumption of a volume increase produces the upper boundaries. Therefore, the actual release fractions for Rods $432-1$ and 432-5 are expected to be near the lower boundary; whereas the release fractions for Rod 432-6 are more appropriately near the upper boundary because of the expected densification in this fuel type.

The gas release fractions from all three rods show three distinct regions: the first extends to $2250 \mathrm{GJ} / \mathrm{kgU}$ ( $3 \mathrm{GWd} / \mathrm{MTM}$ ) and shows little evidence of fission gas release; the second extends to about $1100 \mathrm{GJ} / \mathrm{kgU}$ (13 GWd/MTM) and its gas release fractions increase rapidly with exposure; the release fractions of the last region decrease in Rods $432-5$ and 432-6 but continually increase in Rod $432-1$, although at a slower rate than those in the second region.

As stated previously and shown in Figures 5, 6 and 7 , a direct correlation exists between fuel temperatures and fission gas release. Additional insight into the gas release characteristics can be obtained by considering the thermal resistance of the fuel rod, which is defined as:

$$
R=\frac{T_{c l}-T_{c 00 l}}{q} \cdot \frac{1}{1000}
$$

where: $\quad R=$ thermal resistance, $(K-m / W)$

$$
\begin{aligned}
T_{\mathrm{Cl}} & =\text { local centerline temperature }(\mathrm{K}) \\
T_{\mathrm{cool}} & =\text { coolant temperature }(\mathrm{K}) \\
\mathrm{q} & =\text { local linear heat generation rate }(\mathrm{kW} / \mathrm{m}) .
\end{aligned}
$$

The concept of thermal resistance previously has been described in detail (Lanning et al., 1979); thus, only a brief summary will be given here. 

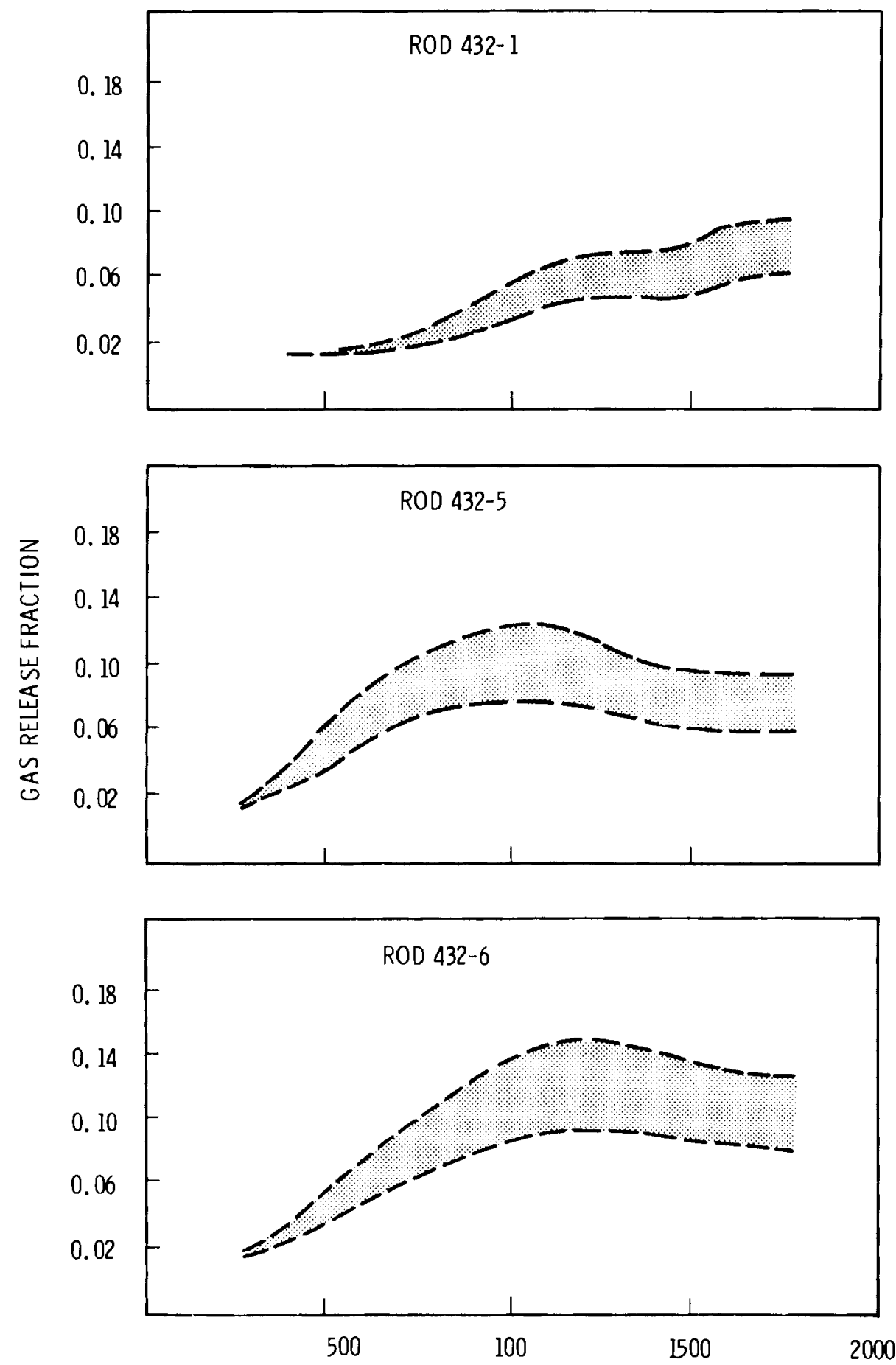

AVERAGE BURNUP, GJ/kgU

FIGURE 8. The Estimated Fission Gas Release Fraction as a Function of Burnup for the IFA-432 Fuel Rods 
The total local resistance of the fuel rod is the sum of the thermal resistance across the cladding, the resistance across the fuel-to-cladding gap, and the resistance through the fuel. Because the cladding resistance changes little as irradiation conditions change, most of the observed changes in resistance reflect either changes in the thermal conductance across the fuel-to-cladding gap or the thermal conductivity of the fuel. Gap size and gas composition are the primary factors influencing the gap conductance, while fuel cracking, gas composition, and fuel microstructures determine the effective thermal conductivity of the fuel.

Fuel cracking, fuel densification, and fuel relocation are the primary mechanisms that alter the resistance during the initial stages of irradiation in which gas release is minimal. Fuel cracking is expected to increase the resistance by decreasing the effective thermal conductivity of the fuel. However, fuel relocation and densification have opposite effects on the gap resistance depending upon their contribution to the gap size. Fuel relocation will decrease the gap size and thereby decrease the gap resistance while densification causes an increase in gap size and, thus, gap resistance. The microstructural changes that accompany densification could increase the thermal conductivity of the fuel but the change in gap size is expected to dominate.

The thermal resistance curves for assembly 432 , rods 1,5 and 6 , all showed the same general trends as a function of burnup. These trends are illustrated in Figure 9 where the thermal resistance from Rod 432-6 at the upper and lower thermocouple positions is shown as a function of burnup. The curves were produced from data taken at full reactor power where differences in resistance at the two locations are minimized.

Figure 9 shows that the resistance at the upper position decreases during the initial $100 \mathrm{GJ} / \mathrm{kgU}$ (1.2 GWd/MTM) exposure while it increases at the lower position. The difference between the two locations is thought to be due to greater fuel relocation at the upper location, which overcomes the effects of fuel cracking and densification and results in a decreasing resistance. The 


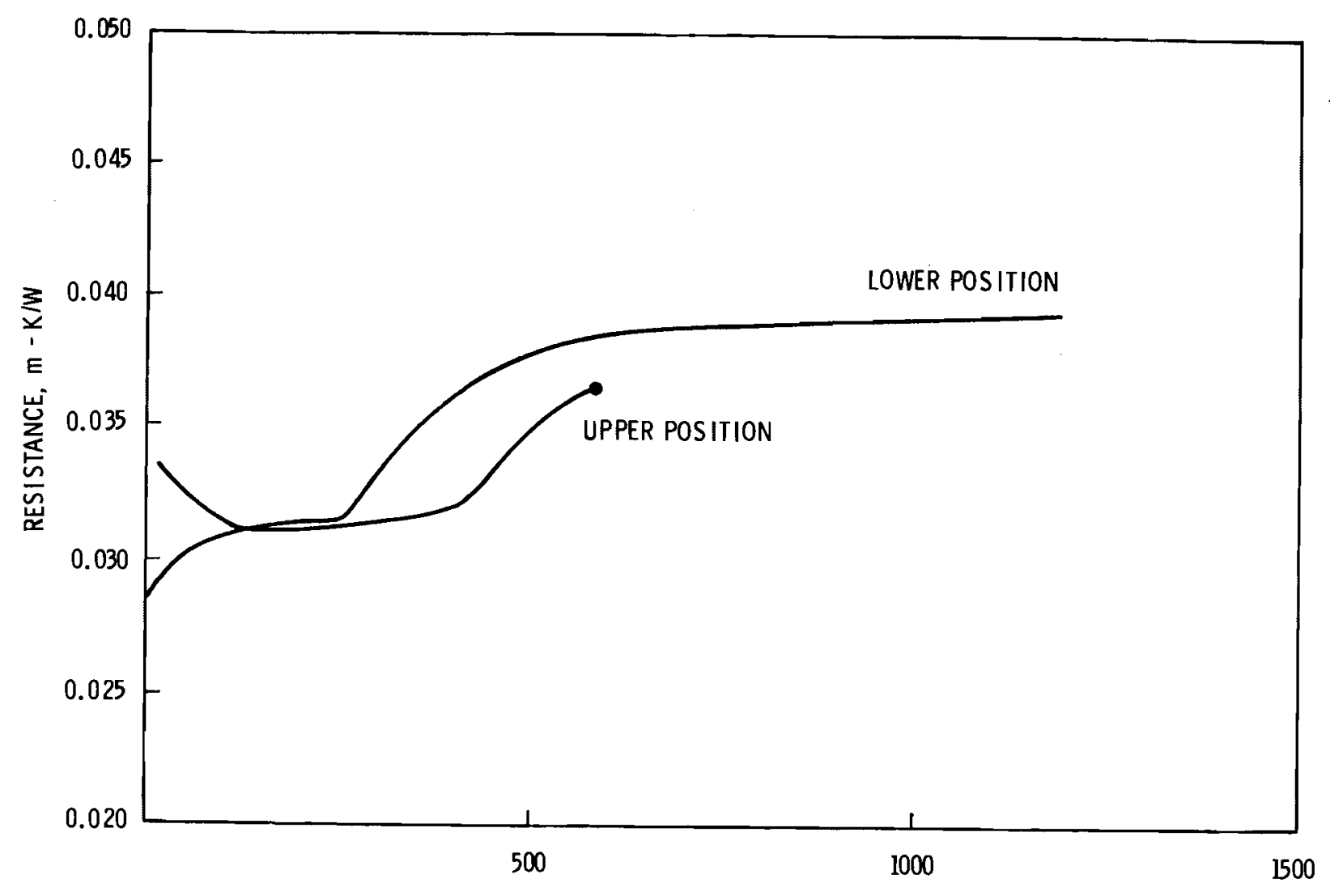

ROD AVERAGE BURNUP, GJ/kgU

FIGURE 9. The Local Thermal Resistances as a Function of Burnup for Rod 432-6

lower power level and increased axial constraint at the lower position reduces relocation so that the resistance increases in response to the effects of fuel cracking and densification.

Following the initial changes, the resistance for both the upper and lower positions increases gradually with exposure to $250 \mathrm{GJ} / \mathrm{kgU}$ ( $3 \mathrm{GWd} / \mathrm{MTM}$ ) where a rapid increase in resistance is observed at the lower location. The gradual increase in resistance could be due to additional fuel cracking or to the release of fission gas. It is not possible to completely identify the responsible mechanism, but a similar gradual increase in resistance was 
observed in Rod 432-3, which operated at lower fuel temperatures (1473K peak centerline). Therefore, if fission gas release is responsible for the gradual resistance increase, the release rates are low and suggest a low-temperature (i.e., knock-out) mechanism for fission gas release during this period.

The rapid increase in the resistance at the lower position is definitely associated with fission gas release as evidenced by the concurrent increase in rod pressure. The resistance continues to increase with increasing gas release until a balance between the effects of gas composition, fuel-tocladding gap size, and the effective fuel conductivity results in constant fuel rod resistances. The saturation of the gas thermal conductivity at high xenon concentrations is thought to be primarily responsible for the constant resistances.

The resistance response at the upper thermocouple position is not completely understood. The smaller gap size at the upper location caused by the higher power levels and greater initial relocation would be expected to reduce the effects of gas composition on the resistance. This is in agreement with the experimental results, but the rapid increase in resistance just prior to the thermocouple failure is difficult to explain. One possible explanation is for gas segregation to occur. Commonly, this is defined as having the heavy fission gases congregate in the lower portion of the fuel rod and thereby increase the degradation of the gas thermal conductivity at this position relative to the upper level. However, the fission gases are primarily being released at the upper level due to the higher temperatures. Thus, one would expect high concentrations of fission gases in this region. In addition, the frequent power changes occuring during the irradiation should provide adequate mixing, especially along the fuel column and, thus, gas segregation of this type does not appear to be a viable mechanism.

Although the differences between the upper and lower positions are not fully understood, the data from this and other experiments (Cunningham et al., 1979) suggest that the resistance at both locations approaches a limiting value of 0.036 to $0.040 \mathrm{~m}-\mathrm{K} / \mathrm{W}$ at higher burnups. This limiting value for the thermal resistance permits estimation of the temperature at the upper position 
after the thermocouples fail. The estimated temperatures will be used later to calculate fission gas release with computer models.

Based on the preceeding discussion, gas release can be considered to consist of an incubation period where low temperature release mechanisms dominate followed by gas releases that are characteristic of the high temperature processes. The existance of an incubation period for gas release is commonly observed experimentally (Vitanza et al., 1979) and is predicted by models based on mechanistic processes (Hargreaves and Collins, 1976 and Rest, 1978). According to the models, the incubation period represents the time required to establish the diffusion pathways from the fuel interior to the surfaces for subsequent release. Grain boundaries are often considered as the predominant diffusion paths and the models require saturation of grain boundaries before significant diffusional release can be obtained.

The time required to saturate the boundaries, i.e., the incubation period, should decrease with increasing temperatures because diffusion is strongly temperature dependent. The fuel resistance data at the lower thermocouple position shows a rapid increase at the end of the incubation period and thereby provides a sensitive measure of the incubation period. For Rods 432-5 and 432-6, the incubation period was $2250 \mathrm{GJ} / \mathrm{kgU}$ ( $3 \mathrm{GWd} / \mathrm{MTM}$ ); Rod 432-1 showed an incubation period of $\sim 300 \mathrm{GJ} / \mathrm{kgU}$ (3.5 GWd/MTM), which is in accordance with the difference in the peak centerline temperatures.

Futher evidence that the incubation period is temperature dependent is obtained from the resistance data from Rods 432-2 and 432-3. Rod 432-2 contained a large as-fabricated gap and ran hotter than the remaining heliumfilled rods, while Rod 432-3 contained a small gap and peak centerline temperatures were generally below 1573K. Accordingly, the incubation period for Rod 432-2 was less than $90 \mathrm{GJ} / \mathrm{kgU}$ ( $1.0 \mathrm{GWd} / \mathrm{MTM})$, while a sharp increase in resistance has not yet been observed in Rod 432-3. However, because of the small gap size in 432-3, the effects of gas composition may not be as easily detected in the thermal resistance data. 
Following the incubation period, the gas release fractions increase as a result of both the onset of high temperature gas release and thermal feedback. This increases the fuel temperatures and concurrently increases the gas release rates. The release fractions continue to increase until the thermal resistance stabilizes and steady-state conditions are achieved. Thereafter, the gas release rates and the release fractions are directly associated with the local power levels and the corresponding fuel temperatures.

The differences in the gas release characteristics of the three rods could be due to differences in their temperature histories, fuel densities, fuel stability, or burnup-enhanced fission gas release. Direct comparisons between the estimated release fractions are not adequate to differentiate between the various possibilities because of the different temperature histories involved. Consequently, we must rely on fission gas release models with different functional dependencies to attempt an assessment of the effect of the experimental parameters.

For this purpose, the fission gas release fractions, as a function of burnup from the three rods, have been compared with the predictions from the gas release models currently being used in the GAPCON and FRAPCON series of steady-state computer codes. Specifically, the GASREL (Beyer et al., 1975), FGASRL (Reymann, ed. 1978), and ANS54 (Rausch and Panisko, 1979) subroutines for fission gas release were used in conjunction with a small computer code for calculating the axial and radial temperature distributions. The results are shown in Figures 10, 11, and 12 for Rods 432-1, 432-5, and 432-6, respectively. 


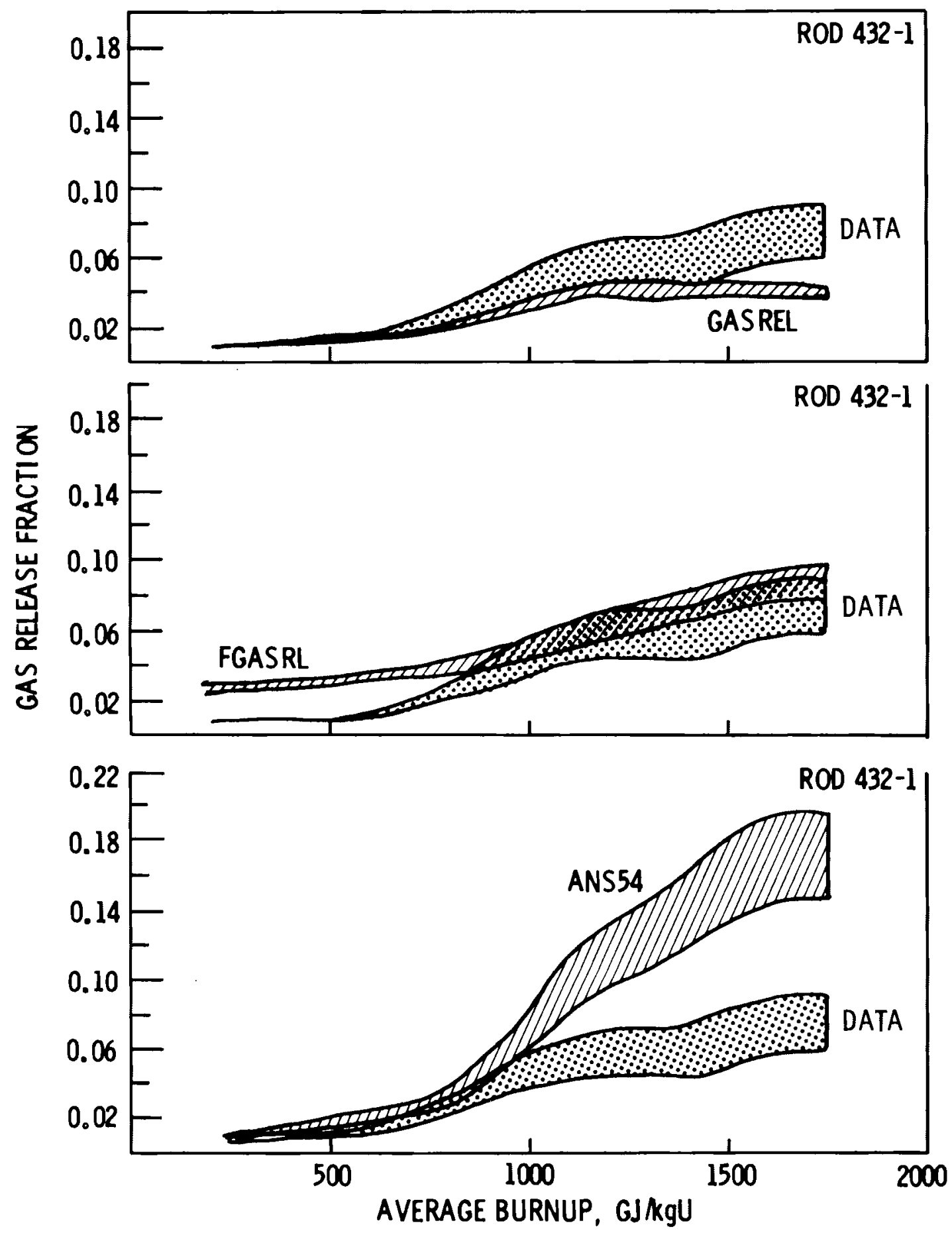

FIGURE 10. Comparison of the Estimated Gas Release Fractions from Rod 432-1 to Those Presicted by GASREL, FGASRL, and ANS54. 

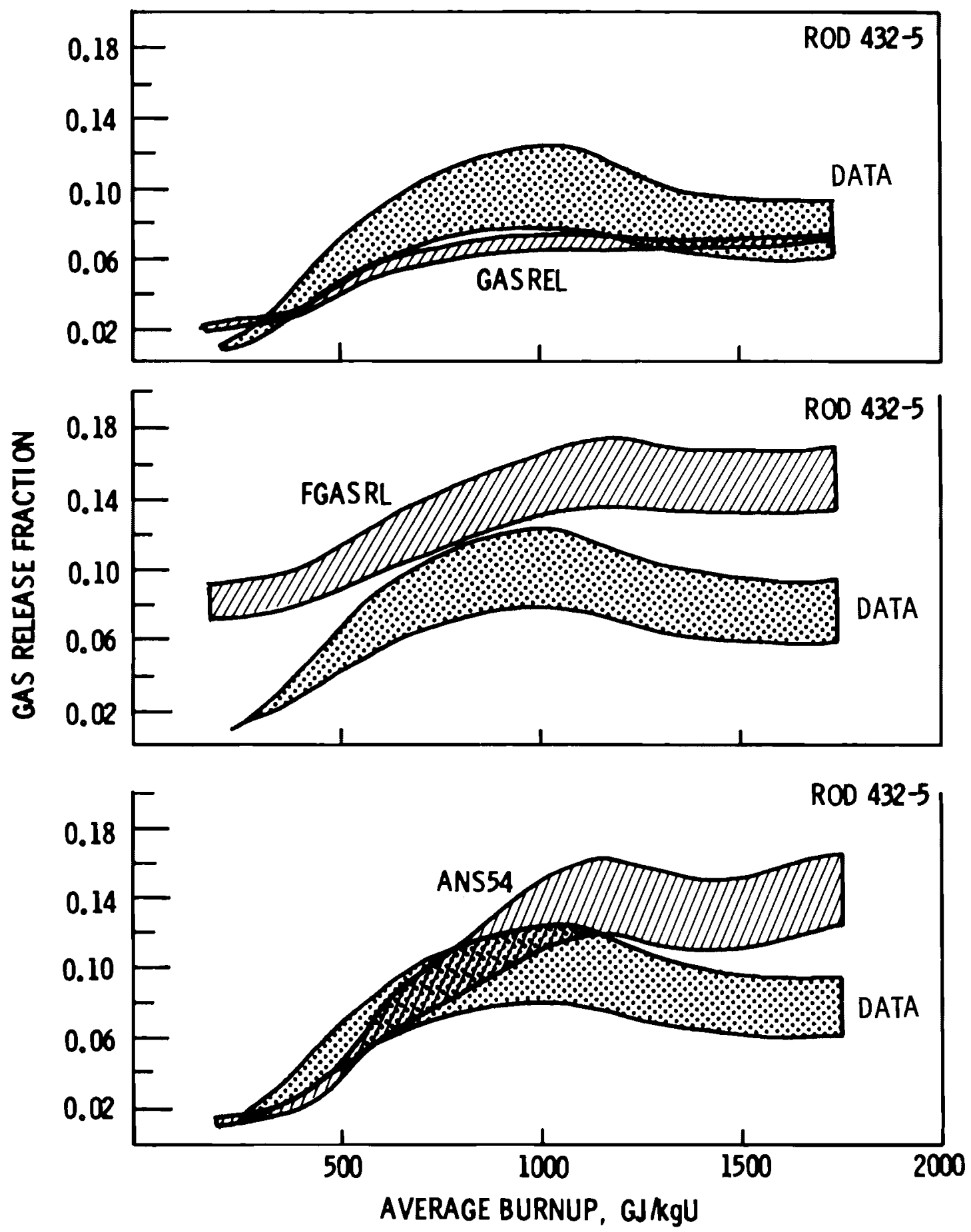

FIGURE 11. Comparison of the Estimated Gas Release Fractions from Rod 432-5 to Those Predicted by GASREL, FGASRL, and ANS54 


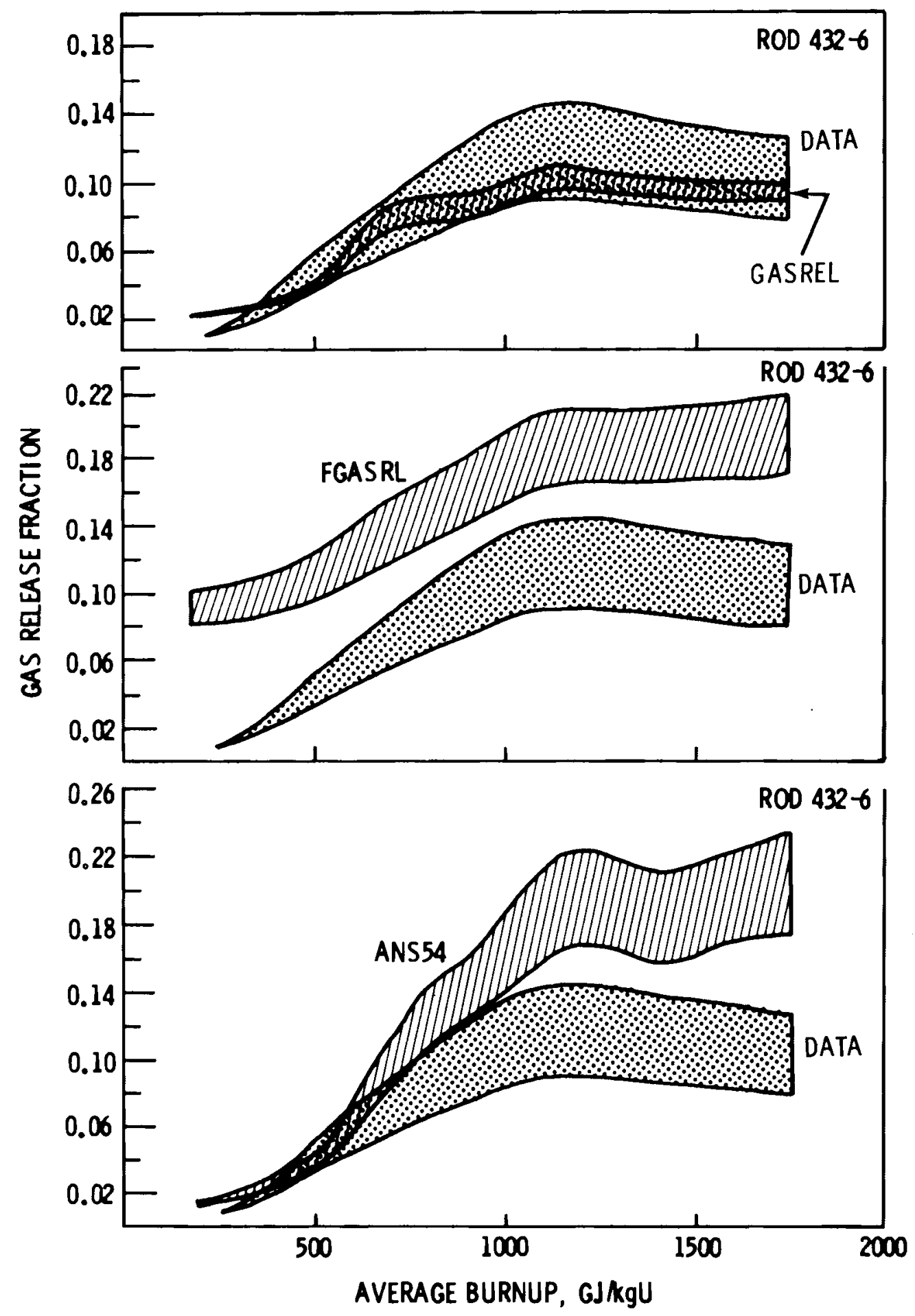

FIGURE 12. Comparison of the Estimated Gas Release Fractions from Rod 432-6 to Those Predicted by GASREL, FGASRL, and ANS54 
The calculations were based on the measured temperature/power histories of the fuel rods. Burnup increments of either 86 or $172 \mathrm{GJ} / \mathrm{kgU}$ ( 1 or $2 \mathrm{GWd} / \mathrm{MTM}$ ) were used and the fuel column was divided into four axial segments, each about $150 \mathrm{~mm}$ long. The measured centerline temperatures were used for the end segments, and the axial power distribution was used to estimate the temperatures at the inner segments. After the upper thermocouples failed, the temperature difference between end segments was estimated from the difference in local power levels assuming a constant thermal resistance of $0.036 \mathrm{~m}-\mathrm{k} / \mathrm{W}$. The radial temperature distributions were calculated from the centerline temperatures with a small computer code that uses the integral conductivity equation. Two separate sets of calculations were made for each fuel rod and gas release model. The first set used the conductivities for each fuel type that were experimentally measured prior to irradiation (Hann et al. 1977). For the second set of calculations, the preirradiated thermal conductivities were decreased by $25 \%$ to simulate the effects of fuel cracking. Decreasing the fuel conductivity reduced the inferred fuel surface temperatures and produced the range of calculated gas release fractions shown in the above figures. Details of the temperature calculations are provided in Appendix $C$.

Figures 10, 11, and 12 show that differences exist between the models with regard to both the magnitude and burnup dependence of fission gas release In genera1, the subroutine GASREL calculates lower release fractions than FGASRL at all burnups. The release fractions from the ANS model tend to approach the values from GASREL at low burnups $[<400 \mathrm{GJ} / \mathrm{kgU}(5.0 \mathrm{GWd} / \mathrm{MTM})]$ and approach or exceed the FGASRL values at higher burnups because of the imposed burnup dependence. Also, the range of calculated gas release fractions is less for GASREL than for either FGASRL or ANS54, which shows a stronger dependence on the radial temperature distribution for the latter models.

As discussed previously, there are uncertainties associated with the release fractions estimated from the pressure data. As such, comparison of the absolute magnitudes of the predicted and measured release fractions should await results from the postirradiation examination. However, the effects of 
burnup enhancement, fuel density, and fuel stability can be examined by comparing the differences between the predicted and the estimated release fractions. A constant difference is expected if the model is correctly predicting fission gas relase as a function of burnup.

To compare the three models, it is convenient to plot the difference between the predicted and measured gas release as a function of burnup as shown in Figure 13. The measured release fractions for Rods $432-1$ and $432-5$ correspond to the assumption that helium loss is responsible for the initial pressure drop, and for Rod 432-6, a volume increase was assumed in calculating the release fractions. Using specific values rather than a range of values for the estimated release fractions clarifies the plots by reducing the overlapping regions but does not change the analysis. However, it should be remembered that a wider range of values exists so that the general trends in the data, rather than specific details, are most important.

The curves derived from GASREL and FGASRL are relatively flat, especially for the rods containing stable fuel (432-1 and 432-5), which indicates that these models are correctly predicting the experimental burnup dependence. Neither of these models contain strong burnup enhancement factors and, therefore, it appears that burnup-enhanced gas release is not significant for burnups to $1700 \mathrm{GJ} / \mathrm{kgU}$ (20 GWd/MTM). In contrast, the strong positive slopes for the data from the ANS 5.4 model can be directly attributed to the model's exponential burnup enhancement factor. In fact, when the burnup-dependent term is removed from the model, the calculated release fractions are very similar in both magnitude and burnup dependence to those predicted by GASREL.

The effects of fuel density on fission gas release can be examined by comparing the results for Rods 432-1 and 432-5 that are obtained from GASREL and FGASRL. Both of these models have a strong dependence on fuel temperatures but GASREL contains a weak dependence on fuel density through its low temperature release model; whereas FGASRL incorporates a strong dependence of fuel density on gas release. Since Rods 432-1 and 432-5 contain different density fuels, it is possible to determine the relative importance of fuel density on gas release by comparing the differences between the predicted and 


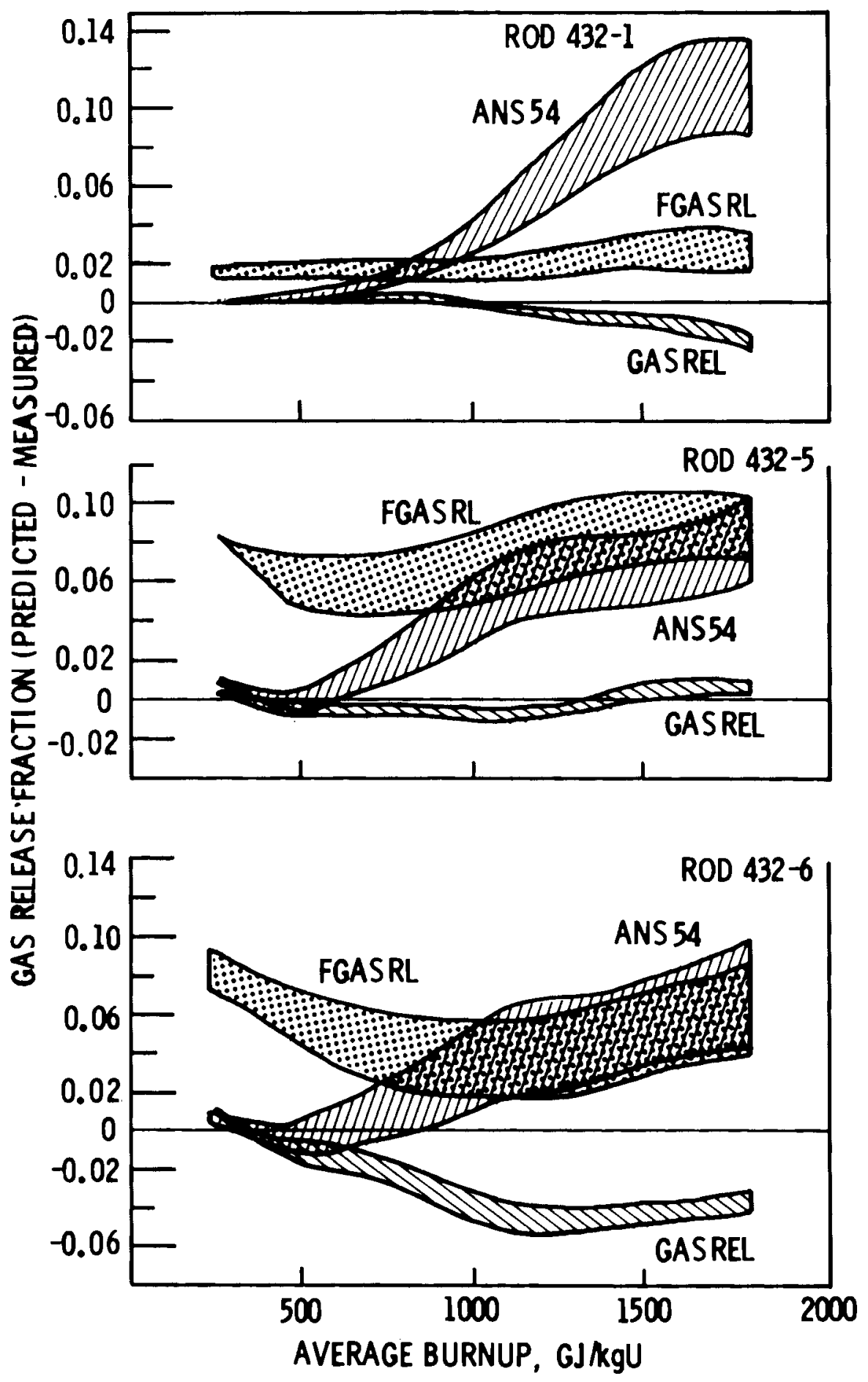

FIGURE 13. A Relative Comparison of the Three Fission Gas Release Models 
measured gas release for these rods. Similar differences between the predicted and measured gas release for both rods are expected if the models temperature and density dependences are correct.

Figure 13 shows that GASREL predicts similar difference; whereas, for FGASRL, the difference between the predicted and measured gas release for Rod 432-5 is about a factor of two higher than for Rod 432-1. These differences between the predicted and measured gas release for both models suggest a weak dependence of fuel density on gas release. However, since the calculated release fractions depend on both the fuel temperature and density, a final assessment of the effects of fuel density on gas release cannot be made until these variables are separated.

To separate them, we have recalculated the release fractions for Rod 432-5 with FGASRL using the same fuel density as Rod $432-1$, i.e. $95 \%$ TD. Thus, fuel density is no longer a variable and the effect of thermal history can be examined. Under these conditions, the difference between the predicted and measured gas release fractions is similar for both rods. Therefore, we can conclude that fuel density is not a significant factor in gas release for typical LWR fuels.

The curves for Rod 432-6 in Figure 13 are somewhat different than those for Rods 432-1 and 432-5 and the differences may be associated with the unstable fue 1 in Rod 432-6. The curves for both GASREL and FGASRL show a decrease with exposure to $21100 \mathrm{GJ} / \mathrm{kgU}$ ( $13 \mathrm{GWd} / \mathrm{MTM}$ ), which indicates that the models are underpredicting the burnup-dependent gas release in this rod. This behavior is likely related to differences in the thermal characteristics of Rod 432-6 associated with the structural changes that occur during densification.

The expected densification in the unstable fuel would increase the available free volume across the diameter of the fuel rod. This increased free volume would lead to either an increase in the fuel-to-cladding gap size or to more frequent and larger cracks within the fuel. Both of these conditions would tend to increase the total thermal resistance of the rod relative to one that had less available free volume. 
Therefore, since we previously assumed the same thermal resistance for all three rods, the temperature difference between the upper and lower positions may have been underestimated for Rod 432-6. However, the magnitude of the effect densification has.on the thermal resistance is very sensitive to the actual distribution of the free volume across the diameter and, therefore, difficult to quantify.

In addition to increasing the thermal resistance, extensive fuel cracking could alter the radial temperature distributions and thereby influence fission gas release. As before, the actual crack distributions and crack sizes would dominate the radial temperature distribution, the magnitude of this effect on gas release has not been established.

In summary, comparison of the estimated gas release fractions to the predictions from GASREL, FGASRL, and ANS54 has shown that:

- Fuel temperature is the predominant factor influencing fission gas release.

- Fuel density has, at most, a minor influence on fission gas release.

- Burnup enhancement of fission gas release is not significant to 21700 GJ/kgU (20 GWd/MTM). 


\section{REFERENCES}

Beyer, C. E., et a1. 1975. GAPCON-THERMAL-2: A Computer Program for Calculating the Thermal Behavior of an Oxide Fuel Rod. BNWL-1898, Pacific Northwest laboratory, Richland, Washington 99352.

Cunningham, M. E., D. D. Lanning and R. E. Williford. 1979. Thermal and Mechanical Behavior of a Xenon-Filled Fuel Rod as a Function of Burnup. NUREG/CR-0749, PNL-3075. Pacific Northwest Laboratory, Richland, WA 99352.

Freshley, M. D., et al. 1976. "Irradiation Induced Densification of $\mathrm{UO}_{2}$ Pellet Fuel." J. Nucl. Mater. 62:138.

Hann, C. R., et al. 1979. Postirradiation Data Analys is for the NRC/PNL Halden Assembly IFA-431. NUREG/CR-0797, PNL-2975, Pacific Northwest Laboratory, Richland, Washington 99352.

Hann, C. R., et al. 1977. Test Design, Precharacterization and Fuel Assembly Fabrication for Instrumented Fuel Assemblies IFA-431 and IFA-432. NUREG/CR-0332, BNWL-1988, Pacific Northwest Laboratory, Richland, Washington 99352 .

Hargreaves, R., and D. A. Collins. 1976. "A Quantitative Model for Fission Gas Release and Swelling in Irradiated Uranium Dioxide." J. Br. Nucl. Energy Soc. $15: 311$.

Lanning, D. D., B. 0. Barnes and R. E. Williford. 1979. Manifestations of Nonl inearity in Fuel Center Thermocouple Steady-State and Transient Data: Implications for Data Analysis. NUREG/CR-0220, PNL-2692, Pacific Northwest Laboratory, Richland, Washington 99352.

Rausch, W. N. and F. E. Panisko. 1979. ANS54: A Computer Subroutine for Predicting Fission Gas Release. NUREG/CR-1213, PNL-3077, Pacific Northwest Laboratory, Richland, Washington 99352.

Rest, J. 1978. GRASS-SST: A Comprehensive, Mechanistic Model for the Prediction of Fission Gas Behavior in U02-base Fuels During Steady-State and Transient Conditions. NUREG/CR-0202, Argonne National Laboratory, Argonne, Illinois.

Reymann, G. A., ed. 1978. MATPRO-Version 10: A Handbook of Materials Properties for use in the Analys is of Light Water Reactor Fuel Rod Behavior. TREE-NUREG-1180, EG\&G Idaho, Inc., Idaho Fa71s, Idaho.

Vitanza, C., E. Kolstad and U. Graziani. 1979. "Fission Gas Release Pellet Fuel at High Burnup." In Proceedings of ANS Topical Meeting on Light Water Reactor Fuel Performance, pp. 361-366. American Nuclear Society, Inc., LaGrange Park, Illinois. 


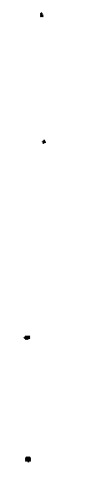


APPENDIX A

PRESSURE DATA FROM IFA-431 AND IFA-432 
TABLE A-1. Pressure Data From IFA-431

\begin{tabular}{|c|c|c|c|c|c|c|c|}
\hline & & Power & Power & Temp. & & sures (M & \\
\hline Date & Time & (MW) & & & Rod 1 & & Rod 6 \\
\hline $506 \quad 75$ & 1727 & 0.00 & 0.0 & 76.0 & 0.102 & 0.140 & 0.196 \\
\hline 50675 & 2225 & 0.00 & 0.0 & 95.3 & 0.110 & 0.110 & 0.182 \\
\hline $\begin{array}{lll}5 & 06 & 75\end{array}$ & 2324 & 0.00 & 0.0 & 107.8 & 0.118 & 0.118 & 0.189 \\
\hline $\begin{array}{lll}6 & 06 \quad 75\end{array}$ & 848 & 0.00 & 0.0 & 157.0 & 0.122 & 0.140 & 0.236 \\
\hline $\begin{array}{lll}6 & 06 \quad 75\end{array}$ & 1811 & 0.00 & 0.0 & 175.1 & 0.132 & 0.132 & 0.305 \\
\hline $\begin{array}{lll}7 & 06 & 75\end{array}$ & 1010 & 0.00 & 0.0 & 230.1 & 0.186 & 0.196 & 0.523 \\
\hline 70675 & 2146 & 0.00 & 0.0 & 228.0 & 0.174 & 0.175 & 0.415 \\
\hline 80675 & 1643 & 2.47 & 15.5 & 239.3 & 0.167 & 0.183 & 0.955 \\
\hline 80675 & 1941 & 5.21 & 32.3 & 239.4 & 0.176 & 0.191 & 1.112 \\
\hline $\begin{array}{lll}8 & 06 \quad 75\end{array}$ & 2200 & 7.80 & 40.3 & 239.8 & 0.182 & 0.211 & 1.086 \\
\hline $906 \quad 75$ & 4 & 9.55 & 47.7 & 240.3 & 0.185 & 0.205 & 1.107 \\
\hline 90675 & 209 & 10.74 & 54.5 & 240.4 & 0.194 & 0.210 & 1.509 \\
\hline 90675 & 301 & 11.02 & 55.1 & 240.5 & 0.201 & 0.218 & 1.431 \\
\hline 90675 & 445 & 10.73 & 53.6 & 240.3 & 0.192 & 0.200 & 1.333 \\
\hline 90675 & 707 & 10.73 & 53.6 & 240.5 & 0.193 & 0.207 & 1.396 \\
\hline 90675 & 1038 & 10.69 & 96.0 & 240.4 & 0.192 & 0.211 & 1.401 \\
\hline $\begin{array}{lll}14 & 06 & 75\end{array}$ & 958 & 1.00 & 0.4 & 227.5 & 0.128 & 0.140 & 1.338 \\
\hline $20 \quad 0675$ & 223 & 0.00 & 0.0 & 229.2 & 0.136 & 0.141 & 1.274 \\
\hline $\begin{array}{lll}20 & 06 & 75\end{array}$ & 1140 & 5.88 & 55.4 & 239.7 & 0.181 & 0.204 & 1.279 \\
\hline $20 \quad 06 \quad 75$ & 1547 & 8.20 & 82.3 & 240.2 & 0.194 & 0.221 & 1.298 \\
\hline $22 \quad 06 \quad 75$ & 1146 & 8.00 & 71.7 & 236.7 & 0.166 & 0.208 & 1.098 \\
\hline $\begin{array}{lll}22 & 06 & 75\end{array}$ & 1553 & 10.22 & 98.4 & 236.3 & 0.200 & 0.228 & 1.171 \\
\hline $\begin{array}{lll}22 & 06 & 75\end{array}$ & 1925 & 10.18 & 99.0 & 236.3 & 0.205 & 0.234 & 1.166 \\
\hline 240675 & 1447 & 5.90 & 61.5 & 240.7 & 0.160 & 0.194 & 0.857 \\
\hline $24 \quad 06 \quad 75$ & 1608 & 6.01 & 60.8 & 240.9 & 0.179 & 0.201 & 1.009 \\
\hline $24 \quad 0675$ & 1743 & 6.23 & 61.1 & 240.4 & 0.181 & 0.201 & 0.921 \\
\hline $24 \quad 0675$ & 2119 & 8.01 & 79.2 & 240.4 & 0.194 & 0.213 & 0.906 \\
\hline $25 \quad 06 \quad 75$ & 708 & 8.18 & 74.3 & 240.3 & 0.192 & 0.213 & 0.970 \\
\hline $\begin{array}{lll}26 & 06 & 75\end{array}$ & 338 & 7.43 & 70.7 & 240.1 & 0.175 & 0.208 & 0.911 \\
\hline $\begin{array}{lll}26 & 06 & 75\end{array}$ & 414 & 7.5 & 64.6 & 240.1 & 0.178 & 0.200 & 0.828 \\
\hline $\begin{array}{lll}26 & 06 & 75\end{array}$ & 1740 & 8.93 & 87.6 & 240.5 & 0.175 & 0.222 & 0.897 \\
\hline $\begin{array}{lll}26 & 06 & 75\end{array}$ & 2304 & & 90.4 & 240.5 & 0.195 & 0.216 & 0.897 \\
\hline $\begin{array}{lll}27 & 06 & 75\end{array}$ & 1725 & 0.00 & 0.0 & 229.1 & 0.117 & 0.126 & 0.857 \\
\hline $\begin{array}{lll}28 & 06 & 75\end{array}$ & 1713 & 10.46 & 102.4 & 236.4 & 0.193 & 0.225 & 0.828 \\
\hline 10775 & 1353 & 10.44 & 97.4 & 236.7 & 0.186 & 0.220 & 0.853 \\
\hline 20775 & 1451 & 10.98 & 98.0 & 236.4 & 0.177 & 0.209 & 0.838 \\
\hline $\begin{array}{lll}307 & 75\end{array}$ & 1448 & 9.88 & 81.0 & 236.3 & 0.168 & 0.205 & 0.764 \\
\hline $\begin{array}{lll}7 & 07 & 75\end{array}$ & 1531 & 10.73 & 95.9 & 236.4 & 0.171 & 0.213 & 0.823 \\
\hline $\begin{array}{lll}8 & 07 & 75\end{array}$ & 2014 & 0.93 & 10.9 & 233.6 & 0.133 & 0.159 & 0.704 \\
\hline $\begin{array}{lll}10 & 07 & 75\end{array}$ & 1716 & 11.15 & 103.9 & 236.9 & 0.178 & 0.220 & 0.784 \\
\hline $\begin{array}{lll}14 & 07 & 7\end{array}$ & 1532 & 10.81 & 106.9 & 236.4 & 0.168 & 0.217 & 0.745 \\
\hline $\begin{array}{lll}16 & 07 & 75\end{array}$ & 1625 & 10.96 & 106.5 & 236.1 & 0.171 & 0.217 & 0.764 \\
\hline $\begin{array}{lll}18 & 07 & 75\end{array}$ & 1719 & 10.86 & 102.2 & 236.2 & 0.155 & 0.214 & 0.706 \\
\hline $2107 \quad 75$ & 1508 & 0.00 & 0.0 & 213.2 & 0.101 & 0.137 & 0.529 \\
\hline
\end{tabular}


TABLE A-1. (Cont inued)

\begin{tabular}{|c|c|c|c|c|c|c|c|}
\hline \multirow[b]{2}{*}{ Date } & & $\begin{array}{l}\text { Reactor } \\
\text { Power }\end{array}$ & $\begin{array}{l}\text { Assembly } \\
\text { Power }\end{array}$ & $\begin{array}{l}\text { Mod. } \\
\text { Temp. }\end{array}$ & \multicolumn{3}{|c|}{ Pressures (MPa) } \\
\hline & Time & $(M W)$ & & & Rod 1 & Rod 5 & Rod 6 \\
\hline $\begin{array}{lll}22 & 07 & 75\end{array}$ & 1141 & 10.35 & 101.2 & 236.9 & 0.142 & 0.217 & 0.769 \\
\hline $2507 \quad 75$ & 1530 & 10.49 & 96.8 & 237.1 & 0.154 & 0.211 & 0.715 \\
\hline $2907 \quad 75$ & 1500 & 10.45 & 99.1 & 237.0 & 0.152 & 0.208 & 0.74 \\
\hline 10875 & 2033 & 0.00 & 0.0 & 225.2 & 0.106 & 0.139 & 0.736 \\
\hline 190875 & 2017 & 11.39 & 99.5 & 235.6 & 0.122 & 0.211 & 0.652 \\
\hline 200875 & 1122 & 0.00 & 0.0 & 224.1 & 0.103 & 0.141 & 0.62 \\
\hline 220875 & 1805 & 11.22 & 97.5 & 235.7 & 0.153 & 0.210 & 0.58 \\
\hline 280875 & 855 & 0.00 & 0.0 & 227.7 & 0.102 & 0.137 & 0.56 \\
\hline $2908 \quad 75$ & 1350 & 11.01 & 69.4 & 235.8 & 0.121 & 0.194 & 0.730 \\
\hline 40975 & 1010 & 11.47 & 98.8 & 235.5 & 0.132 & 0.205 & 0.735 \\
\hline $10 \quad 0975$ & 2159 & 11.31 & 101.5 & 235.9 & 0.126 & 0.212 & 0.632 \\
\hline 110975 & 941 & 0.00 & 0.0 & 229.4 & 0.098 & 0.146 & 0.62 \\
\hline 120975 & 911 & 6.05 & 51.9 & 235.9 & 0.111 & 0.165 & 0.68 \\
\hline 120975 & 1112 & 9.02 & 76.1 & 236.0 & 0.119 & 0.187 & 1.22 \\
\hline $12 \quad 0975$ & 1159 & 10.47 & 85.6 & 236.0 & 0.122 & 0.200 & 0.8 \\
\hline 120975 & 1311 & 11.35 & 91.8 & 235.7 & 0.122 & 0.208 & 1.12 \\
\hline 170975 & 1518 & 11.30 & 96.6 & 235.8 & 0.133 & 0.214 & 0.85 \\
\hline $20 \quad 0975$ & 1051 & 0.00 & 0.0 & 231.8 & 0.102 & 0.138 & 0.6 \\
\hline 11275 & 0 & 0.00 & 0.0 & 76.0 & 0.098 & 0.098 & 0.05 \\
\hline 11275 & 750 & 0.00 & 0.0 & 151.0 & 0.098 & 0.098 & 0.09 \\
\hline 11275 & 1940 & 0.00 & 0.0 & 154.0 & 0.098 & 0.118 & 0 . \\
\hline 21275 & 900 & 1.00 & 9.0 & 208.0 & 0.098 & 0.118 & 0. \\
\hline $7 \quad 1275$ & 1320 & 0.10 & 5.5 & 241.0 & 0.098 & 0.147 & 0 \\
\hline 71275 & 1555 & 0.00 & 0.0 & 236.0 & 0.098 & 0.127 & 0.0 \\
\hline 81275 & 325 & 0.20 & 5.0 & 240.0 & 0.098 & 0.157 & 0 . \\
\hline 81275 & 1120 & 3.80 & 35.0 & 241.0 & 0.147 & 0.176 & 0 \\
\hline 81275 & 1500 & 7.90 & 70.0 & 238.0 & 0.167 & 0.196 & 0 \\
\hline 81275 & 1650 & 8.80 & 81.0 & 231.0 & 0.206 & 0.235 & 0 \\
\hline 91275 & 235 & 0.00 & 0.0 & 221.0 & 0.118 & 0.137 & 0.09 \\
\hline $13 \quad 1275$ & 1440 & 0.00 & 0.0 & 231.0 & 0.098 & 0.137 & 0 \\
\hline $15 \quad 1275$ & 355 & 11.10 & 83.0 & 237.0 & 0.167 & 0.216 & 0.127 \\
\hline $15 \quad 1275$ & 1005 & 11.50 & 82.0 & 237.0 & 0.167 & 0.196 & 0.127 \\
\hline $15 \quad 1275$ & 1400 & 11.10 & 80.0 & 237.0 & 0.176 & 0.176 & 0.118 \\
\hline $16 \quad 1275$ & 220 & 11.40 & 100.0 & 237.0 & 0.176 & 0.196 & 0.137 \\
\hline $16 \quad 1275$ & 915 & 11.40 & 105.0 & 237.0 & 0.176 & 0.186 & 0.127 \\
\hline $16 \quad 1275$ & 1610 & 11.40 & 103.0 & 237.0 & 0.176 & 0.186 & 0.127 \\
\hline $16 \quad 1275$ & 2000 & 11.40 & 95.0 & 237.0 & 0.176 & 0.196 & 0.12 \\
\hline 161275 & 2050 & 11.40 & 97.0 & 237.0 & 0.176 & 0.186 & 0.13 \\
\hline $16 \quad 1275$ & 2340 & 11.80 & 98.0 & 236.0 & 0.167 & 0.186 & 0.13 \\
\hline 171275 & 850 & 9.00 & 72.0 & 236.0 & 0.157 & 0.167 & 0.12 \\
\hline $17 \quad 1275$ & 1325 & 7.10 & 54.0 & 237.0 & 0.147 & 0.157 & 0 . \\
\hline $\begin{array}{lll}18 & 12 & 75\end{array}$ & 730 & 0.00 & 0.0 & 229.0 & 0.108 & 0.118 & 0.098 \\
\hline $\begin{array}{lll}30 & 12 & 75\end{array}$ & 1216 & 0.00 & 0.0 & 221.9 & 0.098 & 0.137 & 0.098 \\
\hline 20176 & 1424 & 11.70 & 103.6 & 236.2 & 0.098 & 0.216 & 0.11 \\
\hline
\end{tabular}


TABLE A-1. (Continued)

\begin{tabular}{|c|c|c|c|c|c|c|c|}
\hline \multirow[b]{2}{*}{ Date } & \multirow[b]{2}{*}{ Time } & $\begin{array}{c}\text { Reactor } \\
\text { Power }\end{array}$ & $\begin{array}{l}\text { Assembly } \\
\text { Power }\end{array}$ & $\begin{array}{l}\text { Mod. } \\
\text { Temp. }\end{array}$ & \multicolumn{3}{|c|}{ Pressures (MPa) } \\
\hline & & (MW) & $(\mathrm{kW})$ & & $\overline{\operatorname{Rod}} 1$ & & $\operatorname{Rod} 6$ \\
\hline 70176 & 958 & 0.00 & 0.0 & 222.3 & 0.098 & 0.127 & 0.098 \\
\hline 230176 & 2131 & 0.00 & 0.0 & 226.3 & 0.098 & 0.127 & 0.098 \\
\hline 240176 & 1628 & 11.30 & 95.1 & 235.7 & 0.098 & 0.196 & 0.108 \\
\hline 240176 & 1647 & 11.20 & 95.1 & 235.7 & 0.098 & 0.196 & 0.108 \\
\hline 50276 & 1556 & 0.00 & 0.0 & 231.1 & 0.098 & 0.118 & 0.098 \\
\hline 60276 & 1443 & 9.30 & 75.2 & 235.2 & 0.098 & 0.196 & 0.108 \\
\hline $\begin{array}{lll}13 & 02 & 76\end{array}$ & 557 & 7.20 & 56.7 & 234.7 & 0.098 & 0.196 & 0.118 \\
\hline 130276 & 1556 & 0.00 & 0.0 & 229.1 & 0.098 & 0.127 & 0.098 \\
\hline $13 \quad 0276$ & 1625 & 0.00 & 0.0 & 228.0 & 0.098 & 0.127 & 0.098 \\
\hline
\end{tabular}


TABLE A-2. Pressure Data From IFA-432

\begin{tabular}{|c|c|c|c|c|c|c|c|}
\hline \multirow[b]{2}{*}{ Date } & & $\begin{array}{c}\text { Reactor } \\
\text { Power }\end{array}$ & $\begin{array}{c}\text { Assemb ly } \\
\text { Power }\end{array}$ & $\begin{array}{l}\text { Mod. } \\
\text { Temp. }\end{array}$ & \multicolumn{3}{|c|}{ Pressures (MPa) } \\
\hline & Time & (MW) & $(\mathrm{kW})$ & (C) & Rod 1 & Rod 5 & Rod 6 \\
\hline 11275 & 745 & 0.00 & 0.0 & 150.0 & 0.144 & 0.15 & 0.175 \\
\hline 11275 & 1930 & 0.00 & 0.0 & 153.6 & 0.142 & 0.15 & 0.188 \\
\hline 21275 & 845 & 1.00 & 11.4 & 108.0 & 0.148 & 0.19 & 0.192 \\
\hline $7 \quad 12 \quad 75$ & 1315 & 0.15 & 7.0 & 240.0 & 0.138 & 0.19 & 0.211 \\
\hline 71275 & 1545 & 0.00 & 0.0 & 235.0 & 0.164 & 0.17 & 0.171 \\
\hline 81275 & 815 & 0.17 & 6.3 & 240.0 & 0.178 & 0.18 & 0.193 \\
\hline 81275 & 1115 & 4.10 & 50.0 & 238.0 & 0.213 & 0.23 & 0.235 \\
\hline 81275 & 1500 & 7.90 & 99.0 & 238.0 & 0.248 & 0.27 & 0.265 \\
\hline 81275 & 1630 & 8.80 & 113.0 & 232.0 & 0.252 & 0.278 & 0.253 \\
\hline 91275 & 215 & 0.00 & 0.0 & 221.0 & 0.182 & 0.168 & 0.182 \\
\hline $13 \quad 1275$ & 1430 & 0.00 & 0.0 & 231.0 & 0.162 & 0.16 & 0.174 \\
\hline $15 \quad 1275$ & 400 & 11.10 & 133.0 & 237.0 & 0.265 & 0.29 & 0.291 \\
\hline $15 \quad 1275$ & 1000 & 11.50 & 133.0 & 237.0 & 0.271 & 0.27 & 0.291 \\
\hline $15 \quad 1275$ & 1330 & 11.05 & 128.0 & 237.0 & 0.270 & 0.27 & 0.271 \\
\hline $15 \quad 1275$ & 1445 & 11.42 & 135.0 & 237.0 & 0.279 & 0.27 & 0.271 \\
\hline $\begin{array}{lll}16 & 12 & 75\end{array}$ & 215 & 11.42 & 138.0 & 237.0 & 0.277 & 0.27 & 0.271 \\
\hline $16 \quad 1275$ & 900 & 11.43 & 140.0 & 237.0 & 0.275 & 0.26 & 0.276 \\
\hline $16 \quad 12 \quad 75$ & 1600 & 11.43 & 141.0 & 237.0 & 0.263 & 0.26 & 0.265 \\
\hline $16 \quad 1275$ & 2045 & 11.43 & 142.0 & 237.0 & 0.271 & 0.270 & 0.257 \\
\hline $16 \quad 12 \quad 75$ & 2330 & 11.80 & 142.0 & 236.0 & 0.270 & 0.26 & 0.253 \\
\hline $17 \quad 1275$ & 845 & 8.99 & 106.0 & 236.0 & 0.236 & 0.230 & 0.230 \\
\hline $17 \quad 1275$ & 1315 & 7.13 & 80.5 & 237.0 & 0.217 & 0.216 & 0.216 \\
\hline $\begin{array}{lll}18 & 12 & 75\end{array}$ & 715 & 0.00 & 0.0 & 229.0 & 0.158 & 0.147 & 0.159 \\
\hline $\begin{array}{lll}19 & 12 & 75\end{array}$ & 730 & 11.15 & 132.3 & 237.0 & 0.266 & 0.266 & 0.266 \\
\hline 191275 & 1415 & 11.78 & 136.0 & 236.0 & 0.265 & 0.250 & 0.265 \\
\hline $\begin{array}{lll}30 & 12 & 75\end{array}$ & 1215 & 0.00 & 0.0 & 222.0 & 0.149 & 0.138 & 0.108 \\
\hline 301275 & 1230 & 0.00 & 0.0 & 222.0 & 0.146 & 0.14 & 0.115 \\
\hline 20176 & 1424 & 11.70 & 138.0 & 236.0 & 0.240 & 0.240 & 0.220 \\
\hline 20176 & 1446 & 11.78 & 138.0 & 236.0 & 0.245 & 0.24 & 0.218 \\
\hline $\begin{array}{lll}7 & 01 & 76\end{array}$ & 1000 & 0.00 & 0.0 & 222.0 & 0.138 & 0.128 & 0.138 \\
\hline 70176 & 1015 & 0.00 & 0.0 & 220.0 & 0.142 & 0.136 & 0.142 \\
\hline $\begin{array}{lll}23 & 01 & 76\end{array}$ & 2130 & 0.00 & 1.1 & 226.0 & 0.128 & 0.11 & 0.108 \\
\hline 240176 & 1630 & 11.30 & 138.0 & 236.0 & 0.210 & 0.210 & 0.210 \\
\hline 240176 & 1645 & 11.20 & 138.0 & 236.0 & 0.210 & 0.210 & 0.210 \\
\hline $\begin{array}{lll}502 & 76\end{array}$ & 1600 & 0.00 & 0.0 & 232.0 & 0.108 & 0.108 & 0.108 \\
\hline $\begin{array}{lll}60276\end{array}$ & 1440 & 9.30 & 113.0 & 235.0 & 0.179 & 0.189 & 0.199 \\
\hline 130276 & 530 & 7.20 & 84.0 & 235.0 & 0.179 & 0.18 & 0.189 \\
\hline $\begin{array}{lll}15 & 02 & 76\end{array}$ & 1500 & 0.00 & 0.0 & 232.0 & 0.119 & 0.119 & 0.119 \\
\hline
\end{tabular}


TABLE A-2. (Cont inued)

\begin{tabular}{|c|c|c|c|c|c|c|c|}
\hline Date & Time & (MW) & $(\mathrm{kW})$ & (c) & Rod 1 & Rod 5 & Rod 6 \\
\hline $25 \quad 0676$ & 730 & 0.00 & 0.0 & 227.0 & 0.131 & 0.125 & \\
\hline 280676 & 1500 & 12.21 & 140.0 & 240.0 & 0.157 & 0.185 & 0.190 \\
\hline 60876 & 1340 & 11.82 & 140.0 & 231.0 & 0.169 & 0.270 & 0.231 \\
\hline 100876 & 1615 & 11.50 & 139.0 & 230.0 & 0.199 & 0.311 & 0.271 \\
\hline $\begin{array}{lll}18 & 08 & 76\end{array}$ & 730 & 0.00 & 0.0 & 225.0 & 0.128 & 0.210 & 0.199 \\
\hline $\begin{array}{lll}18 & 08 & 76\end{array}$ & 800 & 0.00 & 0.0 & 225.0 & 0.103 & 0.180 & 0.172 \\
\hline $\begin{array}{lll}22 & 09 & 76\end{array}$ & 1915 & 0.00 & 0.0 & 234.0 & 0.128 & 0.270 & 0.229 \\
\hline 71076 & 1300 & 0.00 & 0.0 & 227.0 & 0.138 & 0.280 & 0.240 \\
\hline $21 \quad 1076$ & 1300 & 12.30 & 140.0 & 238.0 & 0.280 & 0.695 & 0.523 \\
\hline $29 \quad 1076$ & 1015 & 11.82 & 128.0 & 239.0 & 0.237 & 0.688 & 0.517 \\
\hline $\begin{array}{lll}29 & 1076\end{array}$ & 1930 & 0.00 & 0.0 & 233.0 & 0.138 & 0.356 & 0.311 \\
\hline 71276 & 505 & 2.90 & 9.3 & 238.7 & 0.167 & 0.412 & 0.343 \\
\hline 71276 & 1005 & 4.70 & 41.6 & 240.0 & 0.206 & 0.519 & 0.441 \\
\hline 71276 & 1333 & 9.20 & 109.2 & 240.1 & 0.265 & 0.686 & 0.510 \\
\hline 81276 & 2004 & 3.00 & 13.1 & 239.5 & 0.147 & 0.451 & 0.353 \\
\hline 91276 & 1938 & 11.60 & 123.5 & 240.4 & 0.274 & 0.715 & 0.539 \\
\hline 101276 & 1933 & 12.50 & 146.4 & 239.9 & 0.274 & 0.735 & 0.559 \\
\hline $\begin{array}{lll}3 & 01\end{array}$ & 1434 & 12.40 & 144.0 & 240.1 & 0.304 & 0.843 & 0.706 \\
\hline $\begin{array}{lll}4 & 0177\end{array}$ & 626 & 0.00 & 0.0 & 222.7 & 0.157 & 0.402 & 0.372 \\
\hline $\begin{array}{llll}17 & 77\end{array}$ & 1033 & 11.80 & 135.9 & 239.7 & 0.314 & 0.862 & 0.755 \\
\hline $\begin{array}{lll}19 & 01\end{array}$ & 1038 & 3.00 & 33.9 & 237.0 & 0.186 & 0.637 & 0.578 \\
\hline 190177 & 1511 & 8.50 & 96.3 & 240.4 & 0.216 & 0.823 & 0.735 \\
\hline $\begin{array}{lll}27 & 01\end{array}$ & 930 & 11.90 & 144.1 & 239.3 & 0.333 & 0.921 & 0.843 \\
\hline $\begin{array}{lll}4 & 0277\end{array}$ & 1324 & 4.10 & 66.3 & 235.0 & 0.284 & 0.794 & 0.735 \\
\hline $\begin{array}{lll}9 & 02 & 77\end{array}$ & 1023 & 11.10 & 139.9 & 239.9 & 0.363 & 0.804 & 0.892 \\
\hline $25 \quad 03 \quad 77$ & 1628 & 1.50 & 4.0 & 203.1 & 0.216 & 0.500 & 0.480 \\
\hline $\begin{array}{lll}26 & 03 & 77\end{array}$ & 1233 & 6.50 & 54.8 & 239.3 & 0.314 & 0.784 & 0.715 \\
\hline $\begin{array}{lll}26 & 03 & 77\end{array}$ & 1728 & 12.00 & 116.6 & 239.7 & 0.314 & 0.951 & 0.862 \\
\hline $\begin{array}{lll}10 & 04\end{array}$ & 1034 & 11.70 & 136.6 & 239.4 & 0.392 & 0.862 & 0.970 \\
\hline $14 \quad 04 \quad 77$ & 1458 & 11.50 & 118.6 & 239.2 & 0.382 & 0.892 & 0.970 \\
\hline $\begin{array}{lll}18 & 04\end{array}$ & 1437 & 12.20 & 143.2 & 239.0 & 0.421 & 0.931 & 0.882 \\
\hline $\begin{array}{lll}3 & 0577\end{array}$ & 1313 & 6.20 & 85.8 & 238.7 & 0.441 & 0.931 & 0.902 \\
\hline $\begin{array}{lll}11 & 05 & 77\end{array}$ & 1331 & 12.00 & 138.3 & 238.9 & 0.568 & 1.205 & 1.117 \\
\hline $\begin{array}{lll}16 & 05 & 77\end{array}$ & 1354 & 5.30 & 77.8 & 239.1 & 0.529 & 1.107 & 1.058 \\
\hline 190577 & 2308 & 12.50 & 143.1 & 239.3 & 0.627 & 1.313 & 1.245 \\
\hline 190577 & 2334 & 12.40 & 143.2 & 239.3 & 0.637 & 1.303 & 1.254 \\
\hline $\begin{array}{lll}20 & 05 & 77\end{array}$ & 1300 & 12.40 & 143.0 & 239.5 & 0.627 & 1.303 & 1.245 \\
\hline $20 \quad 05 \quad 77$ & 1500 & 12.30 & 144.0 & 239.4 & 0.637 & 1.303 & 1.235 \\
\hline $\begin{array}{lll}21 & 05 & 77\end{array}$ & 28 & 0.00 & 0.0 & 199.6 & 0.314 & 0.637 & 0.657 \\
\hline $\begin{array}{lll}21 & 05 & 77\end{array}$ & 218 & 0.00 & 0.0 & 198.9 & 0.294 & 0.647 & 0.657 \\
\hline $\begin{array}{lll}21 & 05 & 77\end{array}$ & 1840 & 0.00 & 0.0 & 68.8 & 0.186 & 0.441 & 0.421 \\
\hline
\end{tabular}


TABLE A-2. (Continued)

\begin{tabular}{|c|c|c|c|c|c|c|c|}
\hline \multirow[b]{2}{*}{ Date } & \multirow[b]{2}{*}{ Time } & $\begin{array}{l}\text { Reactor } \\
\text { Power }\end{array}$ & $\begin{array}{l}\text { Assembly } \\
\text { Power }\end{array}$ & $\begin{array}{l}\text { Mod. } \\
\text { Temp. }\end{array}$ & \multicolumn{3}{|c|}{ Pressures (MPa) } \\
\hline & & $\underline{(M W)}$ & & & Rod 1 & Rod 5 & Rod 6 \\
\hline 10577 & 2056 & 0.00 & 0.0 & 70.4 & 0.176 & 0.431 & 0.392 \\
\hline $22 \quad 0577$ & 1950 & 0.00 & 0.0 & 70.6 & 0.245 & 0.461 & 0.500 \\
\hline $16 \quad 0677$ & 1931 & 0.00 & 0.0 & 79.0 & 0.245 & 0.421 & 0.441 \\
\hline 190677 & 2250 & 0.00 & 0.0 & 183.3 & 0.255 & 0.568 & 0.588 \\
\hline 220677 & 1556 & 0.00 & 0.0 & 73.0 & 0.235 & 0.421 & 0.421 \\
\hline 230677 & 555 & 0.00 & 0.0 & 153.1 & 0.284 & 0.519 & 0.519 \\
\hline $24 \quad 0677$ & 921 & 2.90 & 2.1 & 215.7 & 0.412 & 0.862 & 0.853 \\
\hline $24 \quad 0677$ & 1543 & 0.00 & 0.0 & 213.5 & 0.333 & 0.637 & 0.647 \\
\hline $2806 \quad 77$ & 2234 & 2.50 & 21.5 & 200.2 & 0.372 & 0.853 & 0.833 \\
\hline 290677 & 953 & 3.50 & 21.8 & 238.6 & 0.451 & 0.951 & 0.941 \\
\hline 290677 & 1510 & 6.00 & 91.6 & 238.5 & 0.559 & 1.088 & 1.019 \\
\hline $707 \quad 77$ & 1209 & 0.00 & 0.0 & 145.2 & 0.274 & 0.529 & 0.549 \\
\hline $\begin{array}{lll}8 & 07 & 77\end{array}$ & 1954 & 4.60 & 46.0 & 225.2 & 0.480 & 0.882 & 0.862 \\
\hline 90777 & 54 & 11.20 & 127.2 & 235.6 & 0.647 & 1.186 & 1.156 \\
\hline 90777 & 1543 & 11.50 & 139.7 & 237.7 & 0.627 & 1.235 & 1.196 \\
\hline $1107 \quad 77$ & 1151 & 12.10 & 138.0 & 238.4 & 0.647 & 1.245 & 1.225 \\
\hline $\begin{array}{lll}13 & 07\end{array}$ & 1204 & 12.40 & 159.6 & 234.8 & 0.627 & 1.245 & 1.225 \\
\hline $1507 \quad 77$ & 1309 & 0.00 & 0.0 & 206.5 & 0.265 & 0.627 & 0.657 \\
\hline $\begin{array}{lll}1 & 08 & 77\end{array}$ & 1046 & 12.00 & 160.1 & 234.6 & 0.745 & 1.303 & 1.372 \\
\hline 30877 & 1020 & 12.30 & 162.8 & 233.9 & 0.774 & 1.343 & 1.421 \\
\hline 30877 & 1420 & 0.00 & 0.0 & 216.1 & 0.392 & 0.706 & 0.784 \\
\hline 30877 & 1816 & 1.60 & 9.1 & 211.6 & 0.431 & 0.804 & 0.872 \\
\hline 50877 & 1428 & 0.00 & 0.0 & 215.1 & 0.392 & 0.696 & 0.794 \\
\hline $\begin{array}{lll}17 & 08 & 77\end{array}$ & 1415 & 12.10 & 158.6 & 234.0 & 0.872 & 1.382 & 1.509 \\
\hline $\begin{array}{lll}10 & 08 & 77\end{array}$ & 1026 & 12.00 & 161.3 & 233.9 & 0.882 & 1.352 & 1.490 \\
\hline $\begin{array}{lll}22 & 08 & 77\end{array}$ & 1200 & 12.00 & 160.4 & 234.0 & 0.892 & 1.372 & 1.568 \\
\hline $\begin{array}{lll}22 & 08 & 77\end{array}$ & 1314 & 11.90 & 161.0 & 233.8 & 0.902 & 1.362 & 1.548 \\
\hline $\begin{array}{lll}22 & 08 & 77\end{array}$ & 1410 & 11.90 & 160.8 & 234.0 & 0.902 & 1.382 & 1.539 \\
\hline $\begin{array}{lll}26 & 08 \quad 77\end{array}$ & 954 & 12.00 & 164.2 & 234.0 & 0.931 & 1.392 & 1.588 \\
\hline $\begin{array}{lll}26 & 08 & 77\end{array}$ & 1607 & 2.50 & 42.9 & 220.6 & 0.706 & 0.970 & 1.147 \\
\hline $\begin{array}{lll}26 & 08 & 77\end{array}$ & 1659 & 1.80 & 15.7 & 220.1 & 0.598 & 0.951 & 0.960 \\
\hline 141077 & 1622 & 9.20 & 106.7 & 238.4 & 0.862 & 1.352 & 1.568 \\
\hline $15 \quad 1077$ & 1434 & 10.00 & 128.7 & 238.4 & 0.911 & 1.441 & 1.646 \\
\hline 161077 & 1443 & 11.80 & 138.4 & 238.2 & 0.921 & 1.460 & 1.676 \\
\hline 161077 & 1508 & 11.90 & 133.8 & 238.1 & 0.666 & 1.156 & 1.480 \\
\hline $\begin{array}{lll}17 & 10 & 77\end{array}$ & 752 & 12.00 & 131.6 & 238.5 & 0.911 & 1.421 & 1.646 \\
\hline $\begin{array}{lll}17 & 1077\end{array}$ & 1449 & 4.00 & 25.0 & 233.4 & 0.617 & 0.941 & 1.127 \\
\hline $\begin{array}{lll}18 & 10 & 77\end{array}$ & 1208 & 12.70 & 0.7 & 234.3 & 0.549 & 0.833 & 0.990 \\
\hline 191077 & 2038 & 3.90 & 16.6 & 237.8 & 0.598 & 0.931 & 1.098 \\
\hline 191077 & 2101 & 0.00 & 6.3 & 236.8 & 0.480 & 0.725 & 0.911 \\
\hline $24 \quad 1077$ & 937 & 11.40 & 109.2 & 238.6 & 0.882 & 1.372 & 1.597 \\
\hline 291077 & 13 & 10.70 & 118.8 & 239.0 & 0.902 & 1.392 & 1.646 \\
\hline $\begin{array}{lll}31 & 10 & 77\end{array}$ & 808 & 15.20 & 170.5 & 238.6 & 0.941 & 1.519 & 1.784 \\
\hline $\begin{array}{lll}31 & 10 & 77\end{array}$ & 2028 & 15.30 & 174.4 & 238.8 & 0.960 & 1.529 & 1.803 \\
\hline
\end{tabular}


TABLE A-2. (Continued)

\begin{tabular}{|c|c|c|c|c|c|c|c|}
\hline Date & Time & (MW) & $(\mathrm{kW})$ & (c) & Rod 1 & Rod 5 & Rod 6 \\
\hline $\begin{array}{lll}1 & 11 & 77\end{array}$ & 745 & 1.70 & 4.3 & 238.0 & 0.559 & 0.794 & 1.000 \\
\hline $\begin{array}{lll}1 & 11\end{array}$ & 832 & 1.70 & 0.6 & 236.0 & 0.500 & 0.715 & 0.941 \\
\hline $\begin{array}{lll}4 & 71\end{array}$ & 853 & 1.60 & 3.0 & 237.5 & 0.529 & 0.764 & 0.970 \\
\hline 41177 & 902 & 1.70 & 3.2 & 237.7 & 0.529 & 0.784 & 0.970 \\
\hline 41177 & 911 & 1.70 & 3.3 & 237.3 & 0.529 & 0.794 & 0.970 \\
\hline 41177 & 919 & 1.60 & 3.6 & 237.1 & 0.539 & 0.784 & 0.980 \\
\hline 41177 & 926 & 1.60 & 3.7 & 237.2 & 0.529 & 0.794 & 0.980 \\
\hline $\begin{array}{lll}4 & 1177\end{array}$ & 934 & 1.70 & 3.7 & 237.2 & 0.539 & 0.784 & 0.980 \\
\hline 71277 & 1312 & 0.00 & 0.1 & 159.4 & 0.431 & 0.588 & 0.745 \\
\hline 71277 & 2224 & 0.00 & 0.2 & 180.8 & 0.421 & 0.627 & 0.804 \\
\hline $\begin{array}{lll}10 & 12 & 77\end{array}$ & 831 & 2.40 & 5.7 & 238.7 & 0.559 & 0.804 & 0.911 \\
\hline 101277 & 916 & 2.20 & 13.6 & 206.2 & 0.559 & 0.823 & 0.872 \\
\hline $\begin{array}{lll}10 & 12 & 77\end{array}$ & 924 & 2.20 & 14.2 & 207.5 & 0.559 & 0.853 & 0.872 \\
\hline $\begin{array}{lll}11 & 12 & 77\end{array}$ & 2105 & 12.40 & 152.4 & 239.2 & 0.862 & 1.411 & 1.666 \\
\hline $\begin{array}{lll}13 & 12\end{array}$ & 2033 & 2.60 & 8.1 & 238.7 & 0.568 & 0.833 & 0.941 \\
\hline $\begin{array}{lll}13 & 127\end{array}$ & 2044 & 2.60 & 7.9 & 238.9 & 0.559 & 0.843 & 0.951 \\
\hline $13 \quad 1277$ & 2056 & 2.60 & 7.5 & 238.8 & 0.568 & 0.823 & 0.951 \\
\hline $\begin{array}{lll}16 & 12 & 77\end{array}$ & 904 & 2.50 & 5.9 & 238.2 & 0.549 & 0.794 & 0.921 \\
\hline 171277 & 859 & 11.60 & 137.8 & 238.7 & 0.960 & 1.382 & 1.646 \\
\hline $21 \quad 1277$ & 1022 & 11.90 & 137.4 & 238.6 & 0.941 & 1.333 & 1.646 \\
\hline $\begin{array}{lll}21 & 12 & 77\end{array}$ & 1220 & 11.90 & 137.4 & 238.6 & 0.960 & 1.372 & 1.646 \\
\hline $\begin{array}{lll}4 & 01\end{array}$ & 1013 & 11.30 & 156.3 & 238.9 & 0.951 & 1.372 & 1.735 \\
\hline $\begin{array}{lll}5 & 01 & 78\end{array}$ & 935 & 11.20 & 155.8 & 238.7 & 0.882 & 1.372 & 1.715 \\
\hline $\begin{array}{lll}5 & 01 & 78\end{array}$ & 954 & 11.30 & 155.8 & 238.8 & 0.970 & 1.382 & 1.735 \\
\hline $\begin{array}{lll}5 & 01 & 78\end{array}$ & 1050 & 11.30 & 153.8 & 238.8 & 0.970 & 1.372 & 1.725 \\
\hline $\begin{array}{lll}5 & 0178\end{array}$ & 1117 & 11.40 & 153.5 & 230.0 & 0.970 & 1.382 & 1.725 \\
\hline $\begin{array}{lll}5 & 01 & 78\end{array}$ & 1151 & 11.40 & 153.7 & 239.0 & 0.970 & 1.392 & 1.725 \\
\hline 0178 & 1211 & 11.30 & 153.7 & 238.9 & 0.872 & 1.382 & 1.725 \\
\hline 0178 & 1224 & 11.20 & 153.5 & 238.7 & 0.970 & 1.382 & 1.735 \\
\hline 70178 & 931 & 11.60 & 155.6 & 239.0 & 0.872 & 1.372 & 1.725 \\
\hline $\begin{array}{lll}11 & 01\end{array}$ & 848 & 1.50 & 7.3 & 238.5 & 0.578 & 0.823 & 0.970 \\
\hline $\begin{array}{lll}12 & 01 & 78\end{array}$ & 1313 & 11.60 & 158.0 & 239.4 & 0.882 & 1.372 & 1.754 \\
\hline $\begin{array}{lll}12 & 01\end{array}$ & 1331 & 11.40 & 154.6 & 239.2 & 0.882 & 1.382 & 1.744 \\
\hline $\begin{array}{lll}13 & 01 & 78\end{array}$ & 1452 & 1.70 & 8.5 & 238.6 & 0.568 & 0.861 & 1.000 \\
\hline $\begin{array}{lll}13 & 01 & 78\end{array}$ & 1507 & 1.70 & 8.5 & 238.6 & 0.568 & 0.843 & 1.000 \\
\hline 70778 & 1630 & 0.00 & 0.4 & 72.4 & 0.402 & 0.490 & 0.608 \\
\hline $\begin{array}{lll}7 & 07\end{array}$ & 1638 & 0.00 & 0.3 & 72.4 & 0.372 & 0.490 & 0.588 \\
\hline 70778 & 1644 & 0.00 & 0.3 & 72.2 & 0.372 & 0.470 & 0.598 \\
\hline $\begin{array}{lll}7 & 07\end{array}$ & 1651 & 0.00 & 0.3 & 72.4 & 0.372 & 0.470 & 0.617 \\
\hline $\begin{array}{lll}10 & 07\end{array}$ & 911 & 0.00 & 0.2 & 200.2 & 0.557 & 0.706 & 0.931 \\
\hline $\begin{array}{lll}10 & 07\end{array}$ & 918 & 0.00 & 0.1 & 200.3 & 0.578 & 0.706 & 0.931 \\
\hline $10 \quad 07 \quad 78$ & 924 & 0.00 & 0.2 & 200.1 & 0.578 & 0.725 & 0.931 \\
\hline $\begin{array}{lll}10 & 07 & 78\end{array}$ & 931 & 0.00 & 0.1 & 200.3 & 0.568 & 0.813 & 0.9 \\
\hline
\end{tabular}


TABLE A-2. (Cont inued)

\begin{tabular}{|c|c|c|c|c|c|c|c|}
\hline \multirow[b]{2}{*}{ Date } & \multirow[b]{2}{*}{ Time } & $\begin{array}{c}\text { Reactor } \\
\text { Power }\end{array}$ & $\begin{array}{c}\text { Assemb ly } \\
\text { Power }\end{array}$ & $\begin{array}{l}\text { Mod. } \\
\text { Temp. }\end{array}$ & \multicolumn{3}{|c|}{ Pressures (MPa) } \\
\hline & & $(\mathrm{MW})$ & $(\mathrm{kW})$ & & Rod 1 & Rod 5 & Rod 6 \\
\hline $10 \quad 07 \quad 78$ & 938 & 0.00 & 0.2 & 200.1 & 0.568 & 0.706 & 0.931 \\
\hline 100778 & 2032 & 2.10 & 5.0 & 239.9 & 0.647 & 0.853 & 1.117 \\
\hline 100778 & 2030 & 2.10 & 4.8 & 239.5 & 0.617 & 0.843 & 1.049 \\
\hline $10 \quad 07 \quad 78$ & 2039 & 2.10 & 5.2 & 239.4 & 0.608 & 0.833 & 1.049 \\
\hline $\begin{array}{lll}10 & 07 & 78\end{array}$ & 2050 & 2.00 & 5.1 & 239.1 & 0.617 & 0.872 & 1.049 \\
\hline 130778 & 1250 & 3.30 & 11.8 & 239.9 & 0.706 & 0.960 & 1.235 \\
\hline 130778 & 1324 & 4.30 & 22.2 & 238.4 & 0.784 & 1.068 & 1.372 \\
\hline 130778 & 1407 & 6.20 & 36.2 & 239.4 & 0.892 & 1.205 & 1.529 \\
\hline 130778 & 1430 & 7.20 & 43.0 & 239.2 & 0.960 & 1.254 & 1.588 \\
\hline 130778 & 1457 & 8.20 & 49.6 & 238.5 & 0.951 & 1.294 & 1.637 \\
\hline $\begin{array}{lll}13 & 07 & 78\end{array}$ & 1511 & 8.70 & 52.3 & 238.9 & 0.970 & 1.313 & 1.676 \\
\hline 130778 & 1531 & 9.40 & 56.9 & 239.0 & 0.970 & 1.382 & 1.695 \\
\hline $\begin{array}{lll}13 & 07 & 78\end{array}$ & 1558 & 10.30 & 63.7 & 238.9 & 1.000 & 1.372 & 1.754 \\
\hline 130778 & 1619 & 11.00 & 71.1 & 239.4 & 1.029 & 1.421 & 1.793 \\
\hline $1307 \quad 78$ & 1640 & 11.90 & 78.1 & 239.5 & 1.049 & 1.460 & 1.842 \\
\hline $24 \quad 07 \quad 78$ & 945 & 12.30 & 83.1 & 239.9 & 1.049 & 1.490 & 1.852 \\
\hline 10878 & 1355 & 12.50 & 87.4 & 235.5 & 1.058 & 1.509 & 1.891 \\
\hline 40878 & 1450 & 12.70 & 88.8 & 235.7 & 0.980 & 1.519 & 1.891 \\
\hline 40878 & 1505 & 12.70 & 88.5 & 235.8 & 1.078 & 1.519 & 1.911 \\
\hline 40878 & 1512 & 12.70 & 88.3 & 235.8 & 1.058 & 1.529 & 1.911 \\
\hline 70878 & 1822 & 12.30 & 97.0 & 235.7 & 1.088 & 1.519 & 1.950 \\
\hline 70878 & 1829 & 12.40 & 96.8 & 235.9 & 1.078 & 1.539 & -- \\
\hline 90878 & 747 & 2.00 & 5.5 & 239.7 & 0.598 & 0.833 & 1.186 \\
\hline 90878 & 755 & 2.00 & 4.5 & 239.5 & 0.627 & 0.833 & 1.127 \\
\hline $\begin{array}{lll}9 & 08 & 78\end{array}$ & 1059 & 1.50 & 0.2 & 229.9 & 0.559 & 0.745 & 1.098 \\
\hline 140878 & 1107 & 12.60 & 100.9 & 235.0 & 1.117 & 1.597 & 1.999 \\
\hline $14 \quad 0878$ & 1115 & 12.60 & 100.6 & 235.0 & 1.156 & 1.588 & 1.989 \\
\hline $\begin{array}{lll}15 & 08 & 78\end{array}$ & 1440 & 5.20 & 44.7 & 235.3 & 0.921 & 1.294 & 1.666 \\
\hline $22 \quad 08 \quad 78$ & 1634 & 3.90 & 48.7 & 234.9 & 0.951 & 1.303 & 1.686 \\
\hline $22 \quad 0878$ & 1650 & 4.70 & 50.3 & 235.2 & 0.960 & 1.333 & 1.715 \\
\hline $\begin{array}{lll}22 & 08 & 78\end{array}$ & 1706 & 6.30 & 56.2 & 235.3 & 1.019 & 1.372 & 1.784 \\
\hline $28 \quad 08 \quad 78$ & 746 & 12.30 & 101.7 & 233.7 & 1.254 & 1.539 & 2.019 \\
\hline $\begin{array}{lll}28 & 08 & 78\end{array}$ & 758 & 12.40 & 101.6 & 233.5 & 1.147 & 1.578 & 2.019 \\
\hline $\begin{array}{lll}31 & 08 & 78\end{array}$ & 751 & 12.60 & 100.3 & 235.1 & 1.176 & 1.568 & 2.038 \\
\hline 30978 & 2119 & 12.20 & 99.7 & 235.1 & 1.186 & 1.568 & 2.048 \\
\hline 30978 & 2138 & 12.10 & 99.7 & 235.3 & 1.186 & 1.558 & 2.048 \\
\hline 39078 & 2144 & 12.20 & 99.8 & 235.3 & 1.176 & 1.539 & 2.019 \\
\hline 40978 & 743 & 1.70 & 4.1 & 234.6 & 0.676 & 0.843 & 1.147 \\
\hline 40978 & 750 & 1.70 & 3.1 & 234.6 & 0.696 & 0.853 & 1.147 \\
\hline 80978 & 1048 & 12.40 & 96.8 & 235.5 & 1.186 & 1.558 & 1.999 \\
\hline 130978 & 759 & 11.20 & 98.3 & 235.0 & 1.196 & 1.548 & 1.989 \\
\hline $\begin{array}{lll}13 & 09 & 78\end{array}$ & 808 & 11.60 & 98.3 & 234.9 & 1.196 & 1.558 & 2.009 \\
\hline $\begin{array}{lll}15 & 09 & 78\end{array}$ & 753 & 11.90 & 99.7 & 235.1 & 1.196 & 1.558 & 1.999 \\
\hline $20 \quad 0978$ & 758 & 11.80 & 100.9 & 235.2 & 1.196 & 1.519 & 1.999 \\
\hline
\end{tabular}


TABLE A-2. (Continued)

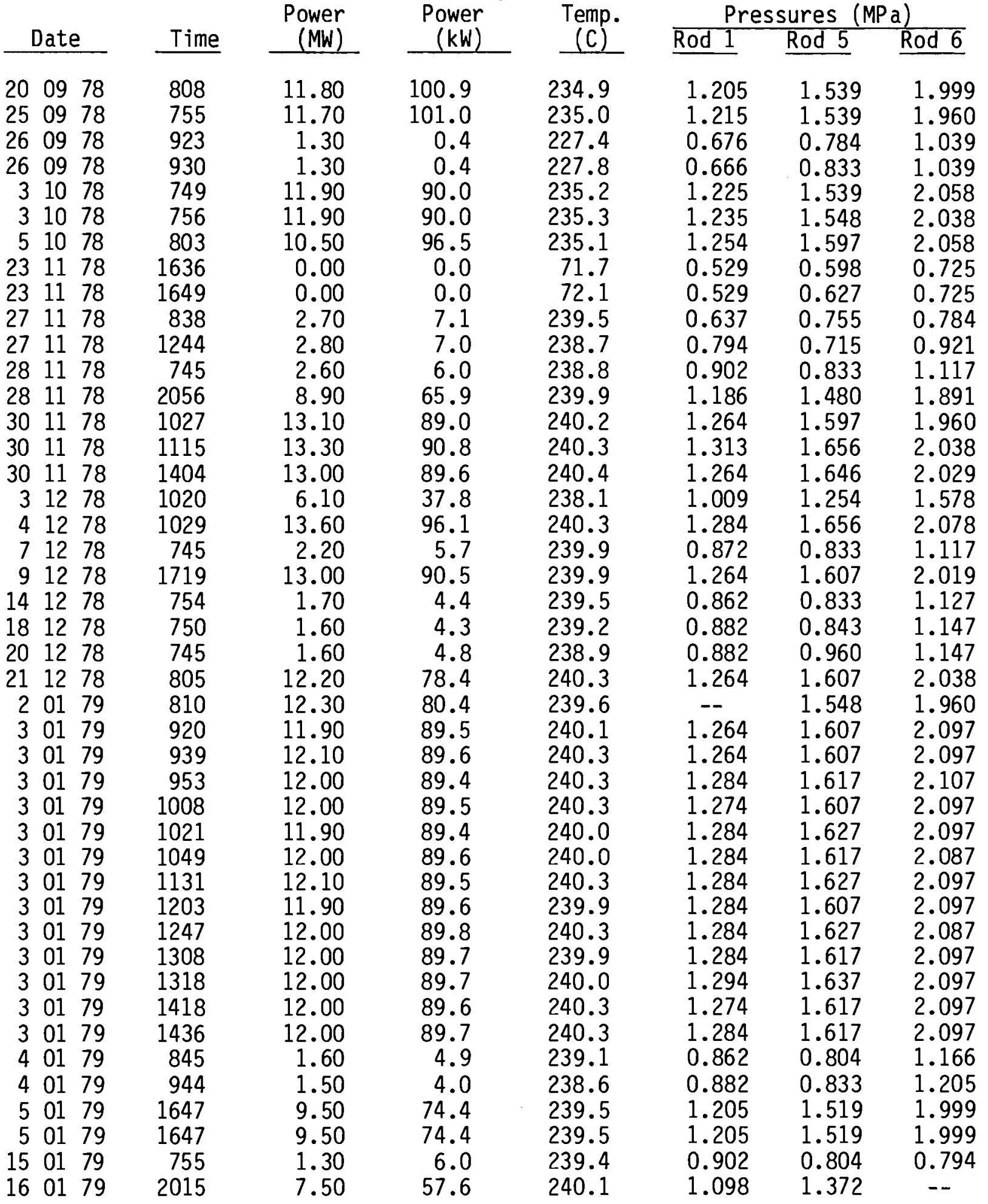


TABLE A-2. (Cont inued)

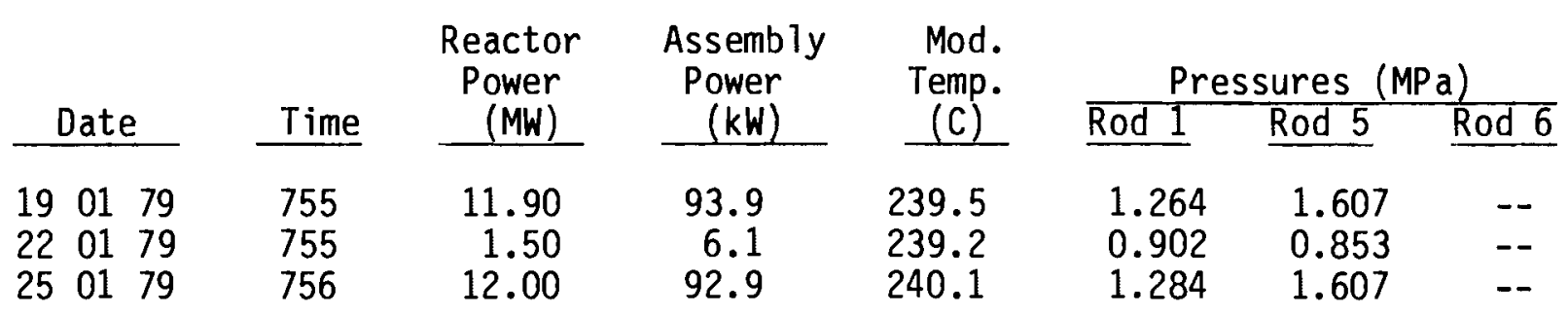


APPENDIX B

ESTIMATED CHANGES IN ROD INTERNAL VOLUME OR GAS CONTENT 
APPENDIX B

ESTIMATED CHANGES IN ROD INTERNAL VOLUME OR GAS CONTENT

A11 pressure data shows a decrease during the initial stages of irradiation that could be due to an increase in the internal free volume and/or a decrease in the helium content of the gas. The estimated pressure decreases due to fuel densification, fuel cracking, helium absorption, and irradiationinduced entrapment are in Table 4. This appendix includes the procedures and assumptions used to estimate the pressure drops for each of these potential mechan isms.

\section{FUEL DENSIFICATION}

Fuel densification provides a logical mechanism for increasing the free volume of a fuel rod. For the fuel rods in IFA-431 and IFA-432, a 1.0\% TD increase corresponds approximately to a $0.5 \mathrm{~cm}^{3}$ increase in the free volume. The fuels in rods 1 and 5 of both assemblies were fabricated to be stable during irradiation, and densification is expected to be less than $0.5 \%$ TD based on the results of resintering tests (Hann et al., 1977). Therefore, the maximum increase in the free volume is expected to be $0.25 \mathrm{~cm}^{3}$. The estimated pressure drops for rods 1 and 5 for each assembly were calculated using this value.

The fue 1 in Rods 431-6 and 432-6 was fabricated to be unstable with respect to densification, and larger volume increases are expected in these rods. Postirradiation examination of Rod 431-6 showed that the density of this fue 1 type increased about $5.0 \%$ TD during irradiation to $2350 \mathrm{GJ} / \mathrm{kgU}$ (4 GWd/MTM). This density increase corresponds to a free volume increase of $2.5 \mathrm{~cm}^{3}$, which was used to estimate the pressure drop due to densification in Rod 432-6.

\section{FUEL CRACKING}

Fuel cracking could increase the free volume of the fuel rod by intersecting and, thus, exposing some of the internal porosity of the fuel. 
An estimate of the amount of porosity exposed by this mechanism can be made by calculating the volume of material affected by the cracks and comparing this to the total volume of the fuel. Multiplying this ratio by the amount of porosity available yields the estimated volume increase. For the calculation, it was assumed that the porosity was uniformly distributed and that the pores contained no gas. The width of the crack-affected zone was taken as twice the median pore diameter of the respective fuel types (Hann et al., 1977).

The calculated volume increases depend directly on the amount of fuel cracking. In the present calculations, one circumferential crack, located at midradius, and four radial cracks were assumed as a reasonable crack distribution. The corresponding free volume increases due to this crack distribution are $0.01 \mathrm{~cm}^{3}$ for Rods $431-1$ and $432-1,0.07 \mathrm{~cm}^{3}$ for Rods $431-5$ and 432-5, and $0.007 \mathrm{~cm}^{3}$ for Rod 432-6. Accordingly, an appreciable increase in the free volumes would require an extremely large amount of cracking. Also, the internal porosity is expected to contain some gases, which reduces the effect of the volume increase. Therefore, the estimated pressure drops listed in Table 4 are believed to represent a maximum pressure drop for this mechanism.

\section{HELIUM ABSORPTION}

A decrease in the amount of heluim present in the fuel rod could result from helium absorption by the $\mathrm{UO}_{2}$. Rufeh et al. (1965) have measured the solubility of helium in $\mathrm{UO}_{2}$ powders (4-um particle size) to be $6.7 \times 10^{-4} \mathrm{cc} \mathrm{He} / \mathrm{atm}-\mathrm{g} \mathrm{UO}{ }_{2}$ at $1473 \mathrm{~K}$. Belle (1958) measured the solubility at $1073 \mathrm{~K}$ and found it to be $2.5 \times 10^{-4} \mathrm{cc} \mathrm{He} / \mathrm{atm}-\mathrm{g} \mathrm{UO} \mathrm{O}_{2}$. Using this data, the amount of helium that could be absorbed in the IFA-431/432 fuels is calculated to be $1.3 \times 10^{-5}$ and $5.1 \times 10^{-6}$ moles for $1473 \mathrm{~K}$ and $1073 \mathrm{~K}$, respectively.

The calculated pressure drops given in Table 4 for helium absorption were obtained from the $1473 \mathrm{~K}$ estimate. These values should represent maximum pressure drops because most of the fuel was below 1473K and fine powders are expected to absorb more helium than solid pellets. 
IRRADIATION-INDUCED ENTRAPMENT

Irradiation-induced entrapment (by knock-on) provides another possible means for reducing the helium content of the fuel rod. Experimental studies on xenon entrapment have shown that the number of xenon atoms entrapped is a linear function of burnup and fill gas pressure (Lewis et al., 1964). The linear dependence on these variables is in agreement with the theory developed by Lewis (1960) for the knock-on process.

Experimental data for helium entrapment during neutron irradiation could not be found and, thus, the data for xenon entrapment (Lewis et al., 1964) was used to estimate the pressure decreases. There is a large amont of scatter in the xenon entrapment data and fuel density appears to be the primary variable. Therefore, the data from fuels with densities greater than $90 \%$ TD was used to estimate the amount of helium that would be entrapped.

In making the estimates, the burnup was taken as $17 \mathrm{GJ} / \mathrm{kgU}(0.2 \mathrm{GWd} / \mathrm{MTM})$ for Rods 431-1 and 431-5 and 170 GJ/kgU (2 GWd/MTM) for the three rods from IFA-432. These values correspond to the exposure required to achieve the minimum pressure in the respective assemblies and thereby represent the potential helium loss during this period. The estimated helium losses are $2.1 \times$ $10^{-6}$ moles for Rods $431-1$ and $431-5$, and $2.1 \times 10^{-5}$ moles for the three rods in IFA-432. The uncertainty in these estimates is quite large because of the big difference in the atomic masses of xenon and helium. However, as discussed in the main report, the pressure data does not show the proper burnup dependency and therefore entrapment does not appear to be a primary mechanism for the initial pressure decreases. 


\section{APPENDIX B REFERENCES}

Hann, C. R., et al. 1977. Test Design, Precharacterization and Fuel Assembly Fabrication for Instrumented Fuel Assemblies IFA-431 and IFA-432. NUREG/CR-0332, BNWL-1988, Pacific Northwest Laboratory, Richland, Washington 99352.

Rufeh, F., D. R. Olander and T. H. Rigford. 1965. "The Solubility of Helium in Uranium Dioxide." Nucl. Sci. and Eng. 23:335.

Belle, J. 1958. "Properties of Uranium Dioxide." In Proceedings of the Second United Nations International Conference on the Peaceful Uses of Atomic Energy Geneva, Switzerland, 6:569.

Lewis, W. B., et al. 1964. "Fission Gas Behavior in U0, Fuel." In Proceedings of the Eleventh International Conference on Peaceful Uses of Atomic Energy, IAEA:405, Vienna, Austria.

Lewis, W. B. 1960. The Return of Escaped Fission Product Gas to $\mathrm{U0}_{2}$. AECL-964, Chalk River, Ontario, Canda. 
APPENDIX C

\section{TEMPERATURE INPUT FOR GAS RELEASE CALCULATIONS}




\section{APPENDIX C TEMPERATURE INPUT FOR GAS RELEASE CALCULATIONS}

Since fuel temperature is the predominant factor influencing gas release, it is the critical input parameter for gas release calculations. The fuel temperature histories used to compare the three gas release models in the main report were based on the measured temperature/power histories at the lower thermocouple position for each rod. The procedures used to estimate the temperatures at the other axial locations are presented in this appendix.

For the gas release calculations, the fuel column was divided into four equal segments. The temperature of each segment was obtained from the relation:

$$
T_{i}=T_{L T C}+B_{i} \Delta T
$$

where $T_{i}=$ center 1 ine temperature of segment $i$

$T_{\text {LTC }}=$ centerline temperature at lower themocouple position, axial segment 1

$\Delta T=$ difference in centerline temperature between upper and lower thermocouples, axial segments 4 and 1

$B_{i}=0.0,0.48,0.79$, and 1.0 for axial segments $1,2,3$, and 4 , respectively.

The specific values for $B$ were obtained from the axial power distribution curve provided by the Halden Reactor Project (Hann et al., 1977).

Plots of fuel temperature vs burnup for each rod were used to determine the average centerline temperature during exposure increments of either $86 \mathrm{GJ} / \mathrm{kgU}(1.0 \mathrm{GWd} / \mathrm{MTM})$ or $172 \mathrm{GJ} / \mathrm{kgU}(2.0 \mathrm{GWd} / \mathrm{MTM})$. Temperature data from the upper and lower themocouple positions was used until the upper thermocouple failed. Thereafter, equation $C-1$ was still used to calculate the temperature for each axial segment, but the temperature difference between the upper and lower locations, $\Delta T$, was estimated by the relation: 


$$
\Delta T=R \Delta q
$$

where $R$ is the fuel rod thermal resistance and $\Delta q$ is the difference in local power between the upper and lower segments.

Using equation $\mathrm{C}-2$ is advantageous because the estimated temperature difference between the upper and lower segments is directly related to the measured difference in local power levels. As discussed in the main report, the measured thermal resistances at the lower thermocouple position saturated in the range of 0.036 to $0.040 \mathrm{~m}-\mathrm{K} / \mathrm{W}$ at full power and the resistances at the upper position appeared to be approaching the same range when the thermocouples failed. There is not enough data available to accurately estimate any' differences in thermal resistance that are due to the local power levels in xenon-filled rods at the upper and lower positions. Therefore, a constant value of $0.036 \mathrm{~m}-K / W$ was used for both locations in calculating $\Delta T$. Figure $\mathrm{C}-1$ shows the temperature histories at the upper and lower positions that were used in the gas release calculations.

The radial temperature distribution for each axial location and burnup increment was calculated with a small computer code. The calculations were based on the fuel centerline temperatures and used the integral conductivity equation. Two separate sets of calculations were made for each fuel rod and gas release model. The first set used the conductivities for each fuel type that were experimentally measured prior to irradiation (Hann, et al. 1977). For the second set of calculations, the preirradiated thermal conductivities were decreased by $25 \%$ to simulate the effects of fuel cracking. This reduced the radial fuel temperatures beyond the centerline position and led to lower gas releases.

The radial temperature distribution is directly used in calculating gas release in all three models. GASREL is a four-temperature-zone model and uses the radial temperature distribution to establish the radial boundaries for each temperature zone. For both the FGASRL and ANS54 models, the fuel is divided into annular rings and the average temperature of each ring is used to 
calculate gas release. Ten annular rings were used in the FGASRL calculations; while twenty rings were used in the ANS54 calculations. The number of annular fuel rings used in the two calculations is in accordance with common practice. Finally, the time-dependent form of the three models was used in order to utilize the experimental temperature/power histories.

The same temperature histories and radial temperature distributions were supplied to each of the gas release subroutines. Hence, even though uncertainties exist in the absolute fuel temperatures, the resulting calculations are directly comparable. 

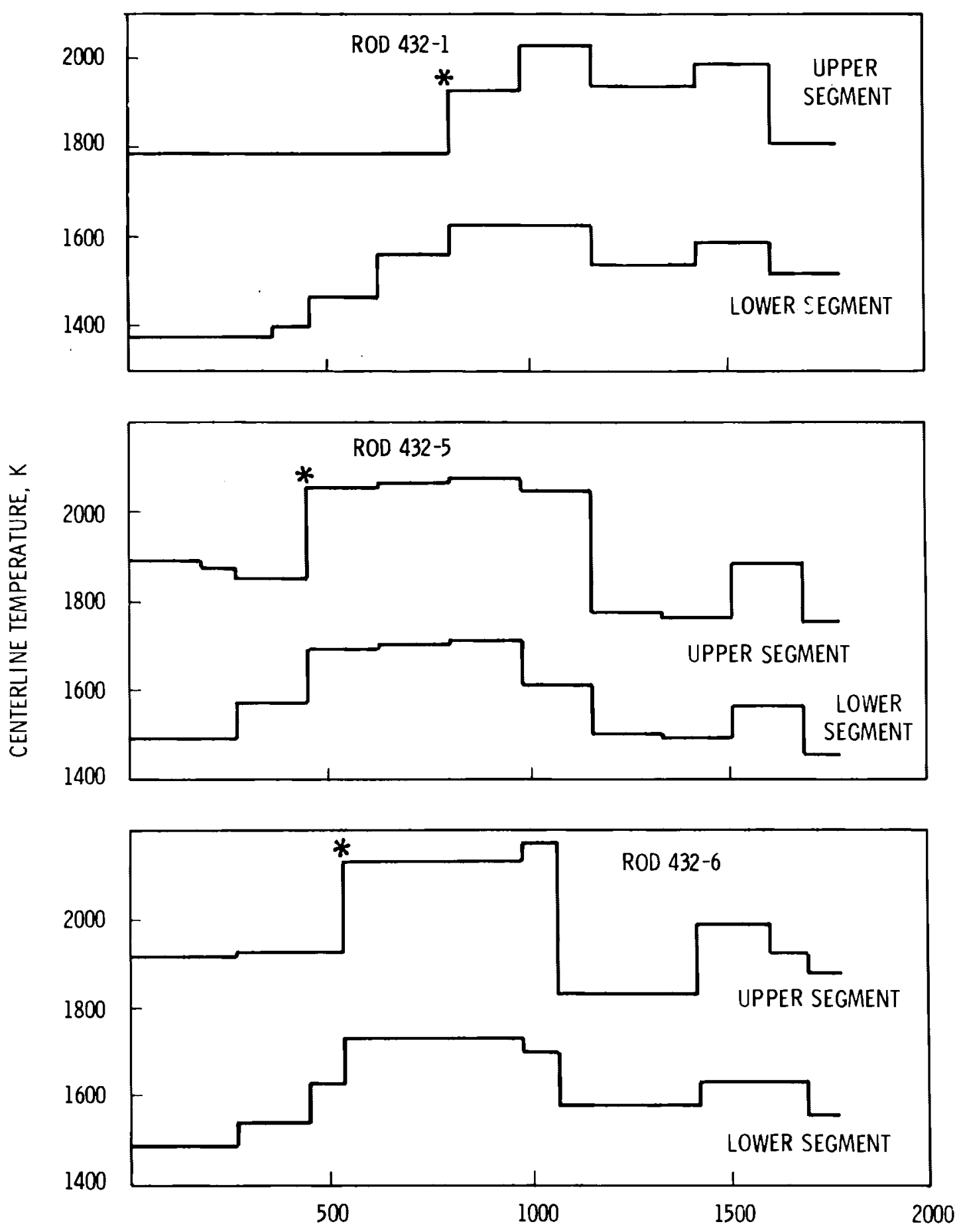

AVERAGE BURNUP, GJ/kgU

FIGURE C-1. Centerline Temperature Histories for Rods 432-1, 432-5, and 432-6 that were Used for Calculating Fission Gas Release (* denotes point at which the thermocouple failed) 


\section{DISTRIBUTION}

No. of

Copies

OFFSITE

A. A. Churm

DOE Patent Division

9800 S. Cass Avenue

Argonne, IL 60439

375 Nuclear Regulatory Commission

Division of Technical Information and Document Control

7920 Norfolk Avenue

Bethesda, MD 20014

2 DOE Technical Information Center

5 W. V. Johnston

Chief, Fuel Behavior Research Branch

Division of Reactor Safety Research

U.S. Nuclear Regulatory Commission

Washington, DC 20555

H. H. Scott

Division of Reactor Safety Research

U.S. Nuclear Regulatory Commission

Washington, DC 20555
No. of

Copies

ONSITE

44 Pacific Northwest Laboratory

W. J. Bailey

J. 0. Barner

S. Begej

E. R. Bradley

E. L. Courtright

M. E. Cunningham

M. D. Freshley

J. F. Garnier

R. L. Goodman

R. J. Guenther

C. M. Hagen

C. R. Hann

K. A. Hsieh

D. D. Lanning

R. K. Marshail

C. L. Mohr (15)

C. Nealley

F. E. Panisko

P. J. Pankaskie

W. N. Rausch

R. E. Schreiber

G. D. White

R. E. Williford

Technical Information Files (5)

Publishing Coordination PA(2) 
